\title{
Reduction of Single Event Kinetic Models by Rigorous Relumping: Application to Catalytic Reforming
}

\author{
H. Cochegrue ${ }^{\text {la }}$, P. Gauthier ${ }^{1 b}$, J.J. Verstraete ${ }^{1}$, K. Surla ${ }^{1}$, D. Guillaume ${ }^{1}$, P. Galtier ${ }^{1}$ and J. Barbier ${ }^{2}$ \\ 1 IFP Energies nouvelles, Rond-point de l'échangeur de Solaize, BP 3, 69360 Solaize - France \\ 2 Université de Poitiers, Laboratoire de Catalyse en Chimie Organique (LACCO), UMR 6503, 40 av. du Recteur Pineau, \\ 86022 Poitiers Cedex - France \\ e-mail: helene.leroy@total.com - mapaomar@uis.edu.co - jan.verstraete@ifpen.fr - karine.surla@ifpen.fr - denis.guillaume@ifpen.fr \\ pierre.galtier@ifpen.fr - jacques.barbier.ji@univ-poitiers.fr \\ ${ }^{a}$ Current adress: TOTAL - CERT, Rogerville, France \\ ${ }^{\text {b }}$ Universidad Industrial de Santander (UIS), Escuela de Ingeniería Química, Bucaramanga, Colombia
}

\begin{abstract}
Résumé - Réduction de modèles cinétiques basée sur les événements constitutifs à l'aide d'un regroupement rigoureux : application au reformage catalytique - La modélisation des procédés de raffinage utilisant des catalyseurs bifonctionnels métal-acide fait intervenir un nombre exponentiellement croissant d'espèces et de réactions qui peut rapidement dépasser plusieurs milliers pour des charges industrielles complexes. Lors de la réalisation d'un modèle de procédé, l'utilisation de modèles cinétiques de regroupement a priori par familles chimiques ne satisfait plus les besoins actuels de simulation détaillée, de prédictivité et d'extrapolabilité. À cause du grand nombre d'étapes élémentaires impliquées dans la catalyse bifonctionnelle, il est déraisonnable de vouloir construire à la main un réseau cinétique détaillé d'une telle ampleur. La génération informatique du réseau réactionnel à partir de règles simples propose une solution élégante dans un tel cas. Malgré cela, l'établissement des équations cinétiques et leur résolution reste difficile, essentiellement à cause du manque de détail analytique demandé par un modèle détaillé. Néanmoins, pour plusieurs procédés de raffinage, des hypothèses raisonnables concernant les équilibres entre espèces permettent d'effectuer un regroupement $a$ posteriori des espèces, réduisant de cette manière la taille du réseau réactionnel tout en maintenant un réseau cinétique entre familles chimiques qui est strictement équivalent au réseau détaillé. Nous présentons ici les outils de génération de réseau et la méthode de regroupement a posteriori associés à la méthode de modélisation cinétique par événements constitutifs. Cette approche de regroupement a posteriori est illustrée et appliquée à la modélisation cinétique des réactions de reformage catalytique.
\end{abstract}

\footnotetext{
Abstract - Reduction of Single Event Kinetic Models by Rigorous Relumping: Application to Catalytic Reforming - Modeling of refining processes using metal-acid bifunctional catalysts involves an exponentially increasing number of species and reactions, which may rapidly exceed several thousands for complex industrial feedstocks. When building a model for such a process, a priori lumped kinetic models by chemical family do no longer meet the current requirements in terms of simulation details, predictive power and extrapolability. Due to the large number of elementary steps occurring in bifunctional catalysis, it would be quite unrealistic to manually build a detailed kinetic network of this scale. Hence, computer generation of the reaction network according to simple rules offer an elegant solution in such a case. Nevertheless, it remains difficult to determine and solve the kinetic equations, mainly due to the lack of analytical detail required by a detailed model. For several refining processes, however, reasonable assumptions on the equilibria between species allow to perform an a posteriori relumping of species, thus reducing the network size substantially while retaining a kinetic network between lumps that is strictly equivalent to the detailed network. This paper describes a network generation tool and the a posteriori relumping method associated with the single-event kinetic modeling methodology. This a posteriori relumping approach is illustrated for and successfully applied to the kinetic modeling of catalytic reforming reactions.
} 


\section{NOTATIONS}

$a$

$C_{H^{+}}$

$C_{M}$

$C_{R_{m}^{+}}$

$C_{O R_{n}^{+}}$

$C_{N R_{o}^{+}}$

$C_{N_{O R}^{+}}$

$C_{D N R_{r}^{+}}$

$C_{\text {tot }, H^{+}}$

$C_{\text {tot, } M}$

$D_{E} N_{A}$

$D E N_{M}$

$h$

$k_{B}$

$k$

$\tilde{k}$

$\bar{k}$

$k_{P r}(m)$

$k_{P r}^{\prime}(m)$

$k_{D e}(m, O)$

$k_{i s o}(m, n)$

$k_{\text {alk }}(m, n)$

$k_{a c y c}(m, n, O)$

$k_{\text {exoN }}(m, n, N O)$ Rate coefficient for cracking of an $m$ cyclic ion into an $n$ ion and a cyclic olefin $N O$

$k_{\text {exoO }}(m, n, O) \quad$ Rate coefficient for cracking of an $m$ cyclic ion into an $n$ cyclic ion and an olefin $O$

$k_{\text {endo }}(m, n)$

Degree of unsaturation of the adsorbed intermediate

Concentration of free acid sites on the catalyst

Concentration of free metal sites on the catalyst

Concentration of an acyclic carbenium ion of type $m$ on the acid sites of the catalyst

Concentration of an acyclic olefinic carbenium ion of type $n$ on the acid sites of the catalyst

Concentration of a cyclic carbenium ion of type $o$ on the acid sites of the catalyst

Concentration of an cyclic olefinic carbenium ion of type $q$ on the acid sites of the catalyst

Concentration of a dicyclic carbenium ion of type $r$ on the acid sites of the catalyst

Total concentration of acid sites on the catalyst

Total concentration of metal sites on the catalyst

Competitive chemisorption term for the acid phase

Competitive adsorption term for the metal phase

Planck's constant

Boltzmann's constant

Rate coefficient of an elementary reaction

Fundamental rate coefficient of an acidcatalyzed single event

Fundamental rate coefficient of a metalcatalyzed event

Rate coefficient for protonation of an olefin into an $m$ type ion

Rate coefficient for protonation of a diolefin into an $m$ type unsaturated ion

Rate coefficient for deprotonation of the $m$ type ion into olefin $O$

Rate coefficient for isomerization of an $m$ ion into an $n$ ion

Rate coefficient for alkylation of an $m$ ion into an $n$ ion

Rate coefficient for cracking of an $m$ ion into an $n$ ion and an olefin $O$

Rate coefficient for cracking of an $m$ cyclic ion into an $n$ unsaturated ion $k_{c y c}(m, n)$

$k_{D M}(u)$

$k_{D E}(u)$

$k_{\text {reac }}\left(L_{1} \Leftrightarrow L_{2}\right)$

$K_{[A \Leftrightarrow B+C]}$

$\widetilde{K}_{[A \Leftrightarrow B]}$

$\widetilde{K}_{[A \Leftrightarrow B+C]}$

$\tilde{K}_{P r / D e}\left(m ; O_{r}\right)$

chirality)

Rate coefficient for cyclization of an $\mathrm{m}$ unsaturated ion into an $n$ cyclic ion

Rate coefficient for demethylation by breaking a bond between a primary carbon atom and carbon atom of type $u$

Rate coefficient for deethylation by breaking a bond between a secondary carbon atom and a carbon atom of type $u$

Rate constant associated with the transformation of lump $L_{1}$ into lump $L_{2}$ according to reactions of type reac

Thermodynamic equilibrium constant for the reaction $A \Leftrightarrow B+C$

Intrinsic thermodynamic equilibrium constant for the reaction $A \Leftrightarrow B$ (excluding the contributions for rotation symmetries and chirality)

Intrinsic thermodynamic equilibrium constant for the reaction $A \Leftrightarrow B+C$ (excluding the contributions for rotation symmetries and Intrinsic protonation/deprotonation equilibrium constant for acyclic carbenium ions of type $m$ into the acyclic reference olefin

$\widetilde{K}_{P r / D e}\left(m ; N O_{r}\right)$ Intrinsic protonation/deprotonation equilibrium constant for cyclic carbenium ions of type $m$ into the cyclic reference olefin

$\tilde{K}_{P r / D e}\left(m ; D O_{r}\right)$ Intrinsic protonation/deprotonation equilibrium constant for acyclic olefinic carbenium ions of type $m$ into the acyclic reference diolefin

$K_{P} \quad$ Adsorption coefficient for paraffins on the metal phase

$K_{N} \quad$ Adsorption coefficient for naphthenes on the metal phase

$K_{D N}$

Adsorption coefficient for dinaphthenes on the metal phase

$K_{A} \quad$ Adsorption coefficient for aromatics on the metal phase

$K_{N A} \quad$ Adsorption coefficient for naphthenoaromatics on the metal phase

$K_{D A} \quad$ Adsorption coefficient for diaromatics on the metal phase

$K_{L_{P}}^{P}$

Chemisorption coefficient for the acyclic olefins linked to paraffin lump $L_{P}$ on the acid phase

$K_{L_{P}}^{P} \quad$ Chemisorption coefficient for the acyclic diolefins linked to paraffin lump $L_{P}$ on the acid phase

$K_{L_{N}}^{N} \quad$ Chemisorption coefficient for the cyclic olefins linked to naphthene lump $L_{N}$ on the acid phase 


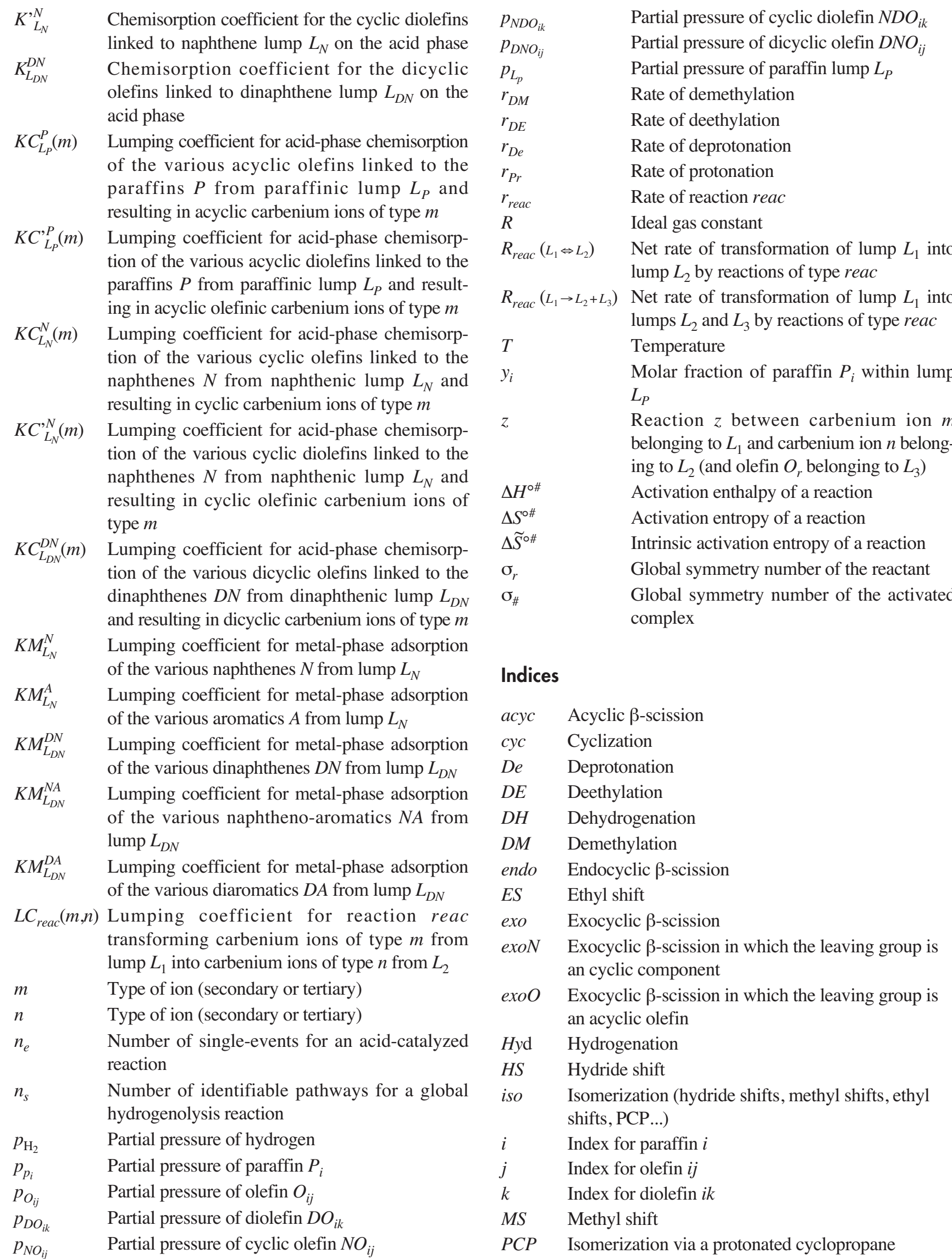




$\begin{array}{ll}\mathrm{Pr} & \text { Protonation } \\ \text { reac } & \text { Reaction } \\ r & \text { Reference compound }\end{array}$

\section{Abbreviations}

$\begin{array}{ll}\text { P } & \text { Paraffin } \\ \text { N } & \text { Naphthene } \\ \text { A } & \text { Aromatic } \\ \text { O } & \text { Olefin } \\ \text { NO } & \text { Cyclic olefin } \\ \text { DNO } & \text { Dicyclic olefin } \\ \text { DO } & \text { Diolefin } \\ \text { NDO } & \text { Cyclic diolefin } \\ \text { nP } & \text { Linear paraffins }\end{array}$

moP Monobranched paraffins

diP Dibranched paraffins

triP Tribranched paraffins

$\mathrm{nN} \quad$ Unsubstituted naphthenes and aromatics

moN Monobranched naphthenes and aromatics

diN Dibranched naphthenes and aromatics

triN Tribranched naphthenes and aromatics

teN Tetrabranched naphthenes and aromatics

$\mathrm{nDN}$ Unsubstituted dinaphthenes, naphthenoaromatics and diaromatics

moDN Monobranched dinaphthenes, naphthenoaromatics and diaromatics

diDN Dibranched dinaphthenes, naphthenoaromatics and diaromatics

triDN Tribranched dinaphthenes, naphthenoaromatics and diaromatics

WHSV Weight hourly space velocity

\section{Sets}

$\{a\}$ Set of all acyclic saturated ions present on the acid phase

$\{b\}$ Set of all acyclic unsaturated ions present on the acid phase

$\{c\}$ Set of all cyclic saturated ions present on the acid phase

$\{d\} \quad$ Set of all cyclic unsaturated ions present on the acid phase

$\{e\} \quad$ set of saturated ions from paraffin $P_{i}$

$\{n\}$ Set of all dicyclic unsaturated ions present on the acid phase

$\{m\} \quad$ Set of unsaturated ions from paraffin $P_{i}$

$\{s\} \quad$ Set of secondary saturated ions from paraffin $P_{i}$

$\{t\} \quad$ Set of tertiary saturated ions from paraffin $P_{i}$

$\{P\} \quad$ Set of paraffins belonging to lump $L_{P}$

$\{N\} \quad$ Set of naphthenes from lump $L_{N}$
$\{A\} \quad$ Set of aromatics from lump $L_{N}$

$\{D N\}$ Set of dinaphthenes from lump $L_{D N}$

$\{N A\}$ Set of naphthenoaromatics from lump $L_{D N}$

$\{D A\}$ Set of diaromatics from lump $L_{D \mathrm{~N}}$

$\left\{L_{P}\right\} \quad$ Set of paraffin lumps

$\left\{L_{N}\right\} \quad$ Set of naphthene lumps

$\left\{L_{D N}\right\} \quad$ Set of dinaphthene lumps

$\{z\} \quad$ Set of reaction steps of type reac transforming the carbenium ions from lump $L_{1}$ into carbenium ions from lump $L_{2}$

$\left\{z^{\prime}\right\} \quad$ Set of reaction steps of type reac transforming the carbenium ions from lump $L_{2}$ into carbenium ions from lump $L_{1}$

$\left\{z_{m n}\right\}$ Set of reaction steps of type reac involved in an $m-n$ transformation of carbenium ions of type $m$ from lump $L_{1}$ into carbenium ions of type $n$ from $L_{2}$

\section{Symbols}

$\rightarrow \quad$ Irreversible reaction

$\Leftrightarrow \quad$ Reversible reaction

\section{INTRODUCTION}

Catalytic reforming is one of the main processes in the refining industry. Its importance is illustrated by the fact that the quantity of feedstock processed is over $20 \%$ of the total crude oil processed in the USA and over 15\% in Western Europe (True and Koottungal, 2010). The main objective of catalytic reforming is the transformation of petroleum fractions with a low Research Octane Number into a high octane reformate, a major blending product for motor gasolines and an important source of aromatic hydrocarbons. Valuable byproducts are hydrogen and liquefied petroleum gas, in which isobutane is the major component.

To improve the octane number of these petroleum fractions, the main reactions, which have to be promoted in order to increase the octane rating, are:

- isomerization of $n$-paraffins into isoparaffins;

- dehydrogenation of six-membered ring naphthenes into aromatics;

- dehydroisomerization of five-membered ring naphthenes into aromatics;

- dehydroaromatization of paraffins into aromatics.

The latter contains the most desired reactions since they yield the largest octane improvement. Several side reactions, which have related mechanisms, also occur during the reforming process. The most important of these reactions are:

- hydrocracking and hydrogenolysis of paraffins and naphthenes;

- hydrodealkylation of aromatics;

- disproportionation of aromatics;

- coke formation. 
Although cracking also leads to an octane improvement, these reactions are considered to be disadvantageous, since they result in a decrease of the yield of liquid reformate. Coke formation covers the catalyst surface with hydrocarbon residues, which are formed via extensive dehydrogenation and polymerization. In this way, it strongly reduces the catalyst activity and is therefore detrimental to the reforming process.

A reforming unit usually consists of three to four adiabatic gas-phase reactors in series. The catalyst distribution over these reactors is generally optimized, resulting in reactors of different sizes (Martino, 1998). Since the main reforming reactions are endothermic, the temperature of the process gas decreases continuously as it passes through the catalyst bed. The effluent from a reactor is therefore reheated to the desired reaction temperature in an inter-reactor furnace before admitting to the next reactor. The liquid effluent after the last reactor is stabilized and the resulting reformate contains 60 to $70 \mathrm{wt} \%$ aromatics, leading to Research Octane Number ranging from 95 to 105 . The remaining fraction mainly consists of paraffins, since nearly all naphthenes are converted. The olefinic fraction generally remains below $1 \mathrm{wt} \%$, due to the high partial pressures of hydrogen.

The reactor inlet temperatures are the primary control variables. The octane number of the reformate can be increased by applying higher reactor temperatures, which are favorable from both a thermodynamic and a kinetic viewpoint. High temperature, however, also favors the undesirable cracking and coking side reactions, resulting in an important yield loss and in a rapid catalyst deactivation. Hence, the applied operating temperatures are arrived at by making a trade-off between the desired product quality, on the one hand, and the product yield and catalyst deactivation, on the other. To select the most appropriate operating conditions for a given feedstock and catalyst, process models have become essential tools.

Process models for optimizing refining and petrochemical processes need to be increasingly more detailed, firstly to account for the extensive diversity of feedstocks and, secondly, to account for the increasingly strict specifications on product quality. The number of species involved in petroleum processes increases exponentially with the number of carbon atoms of the species involved. The number of species quickly exceeds several hundred, or even thousand, molecules. A detailed molecular analysis of the feedstocks and effluents soon proves impossible and it is practically unfeasible to describe a detailed reaction network manually. Use of computers pushes back the limits of "manual" modeling considerably, by allowing to tackle three of the problems related to detailed modeling of large networks: generating the reactions, species and their properties, writing the kinetic equations with their parameters, and simulating reactors using such a detailed kinetic model.
Generation of reactions and reaction networks falls under the larger concept of "computer-assisted chemistry". This vast field of "computer-assisted chemistry" comprises a large variety of applications such as kinetics packages, network generation programs, tools for design of experiments, property estimation methods, structure elucidation software, structure visualization applications, computational chemistry, quantum chemistry, force field methods, computer-assisted organic synthesis planners, and many more. Reverting to reaction networks, several automated network generation algorithms are available in the literature, both for computer aided organic synthesis and for kinetic and reactor modeling purposes. Ugi et al. (1993) tried to classify them and identified three types of network generation methods: empirical methods, semi-formal methods and formal methods. According to their classification, empirical methods are based on pre-established reaction libraries and expert systems. Examples of such databases can already be found in the 1960s (Vleduts, 1963) and continue to be developed (Ihlenfeldt and Gasteiger, 1996). Semi-formal techniques are based on heuristic algorithms that generate reactions, either overall reactions or elementary steps, in a network from a few basic reaction types, but do not have selection procedures to remove improbable reactions from the set of conceivable solutions. Formal techniques generate the various elementary steps at the mechanistic level by taking into account the physical and chemical description of the molecule, while selecting from all possibilities those reactions to be retained in the network in a second step.

Many automated network generation algorithms have been developed and described in the literature for different applications: hydrocarbon pyrolysis (Clymans and Froment, 1984; Hillewaert et al., 1988; Chinnick et al., 1988; Froment, 1991; Dente et al., 1992; DiMaio and Lignola, 1992; Broadbelt et al., 1994, 1995; Susnow et al., 1997; DeWitt et al., 2000; Faulon and Sault, 2001; Kruse et al., 2001, 2002, 2003; Matheu et al., 2001, 2003; Grenda et al., 2003; Klein et al., 2006; Van Geem et al., 2006, 2008; Levine and Broadbelt, 2009), hydrocarbon oxidation and combustion (Chevalier et al., 1990, 1992; Ranzi et al. 1995; Blurock, 1995; Côme et al., 1996; Gaffuri et al., 1997; Glaude et al., 1997, 1998; Iyer et al., 1998; Warth et al., 2000; Battin-Leclerc et al., 2000; Green et al., 2001; Matheu et al., 2001; Németh et al., 2002; Ratkiewicz and Truong, 2003, 2006; Song et al., 2003; Katare et al., 2004; Buda et al., 2006; Pfaendtner and Broadbelt, 2008a, b), isomerization (Guillaume et al., 2003; Surla et al., 2011), alkylation (Martinis and Froment, 2006), olefin oligomerization and alkylation (Prickett and Mavrovouniotis, 1997c; Guillaume, 2006; Shahrouzi et al., 2008), propane aromatization (Katare et al., 2004) catalytic reforming (Joshi et al., 1999; Klein et al., 2006; Wei et al., 2008; Sotelo-Boyás and Froment, 2009), catalytic cracking (Feng et al., 1993; Prickett and Mavrovouniotis, 1997a; Joshi et al., 1997, 1998; 
Dewachtere et al., 1999; Christensen et al., 1999; Moustafa and Froment, 2003; Froment, 2005; Quintana-Solórzano et al., 2007a, b), hydrocracking (Baltanas and Froment, 1985; Baltanas et al., 1989; Vynckier and Froment, 1991; Quann and Jaffe, 1992, 1996; Quann, 1998; Martens and Froment, 1999; Mizan and Klein, 1999; Martens et al., 2000, 2001; Thybaut and Marin, 2003; Laxmi Narasimhan et al., 2003, 2004; Chavarría-Hernández et al., 2004, 2008; Jaffe et al., 2005; Klein et al., 2006; Kumar and Froment, 2007a, b), hydrotreating (Hou and Klein, 1999; Klein et al., 2006), methanol-to-olefins (Park and Froment, 2001, 2004; Al Wahabi and Froment, 2004; Froment, 2005), FischerTropsch synthesis (Klinke and Broadbelt, 1999; Temkin et al., 2002; Lozano et al., 2006, 2008), coke formation (Moustafa and Froment, 2003; Quintana-Solórzano et al., 2005), silicon hydride clustering (Wong et al., 2002), hydrocarboxylation (Zeigarnik et al., 1997), carbonylation (Bruk et al., 1998), organic synthesis (Fountain and Reitsam, 1991), and many more. This illustrates that automated network generation techniques are well suited for any type of reactions, as long as one can define the transformations that are typical of a particular system. Most of these algorithms generate an exhaustive list of the vast number of reactions, thus avoiding error-prone manual reaction network development. Good overviews of some of these automated network generation methods for different applications can be found in Ugi et al. (1993), Prickett and Mavrovouniotis, (1997b), Tomlin et al. (1997) and Klein et al. (2006).

At the Ghent University, a semi-formal network generation algorithm has been developed to generate reaction networks for hydrocarbons (paraffins, naphthenes, aromatics...). The computer algorithm was initially developed for the radical chemistry occurring during thermal cracking (Clymans and Froment, 1984; Hillewaert et al., 1988; Willems and Froment, 1988a, b), later adapted for acid-catalyzed processes (Baltanas and Froment, 1985; Baltanas et al., 1989; Vynckier and Froment, 1991), and recently extended to metal catalyzed processes (Lozano et al., 2006, 2008). This semiformal algorithm allows to exhaustively generate all reactions, intermediates and products at the mechanistic level for a given feedstock, and will be used in this work.

Once the reaction network has been fully described, the kinetic equations of each reaction must be written, while utilizing a limited number of parameters, so that they remain significant and mathematically identifiable. Using the concept of local reactivity and single-events, all reactions occurring on the acid phase of the catalyst can be described with a limited and fixed number of parameters (Baltanas and Froment, 1985; Vynckier and Froment, 1991; Feng et al., 1993; Svoboda et al., 1995; Dewachtere et al. 1999; Froment, 1999, 2005; Martens et al., 2001; Thybaut and Marin, 2003; Moustafa and Froment, 2003; Park and Froment, 2004; Laxmi Narasimhan et al., 2004; Martinis and Froment, 2006; Kumar and Froment, 2007a, b; Mitsios et al., 2009; Surla et al., 2011). Indeed, the chemistry of hydrocarbons on acid catalysts is well known (Brouwer, 1980; Olah et al., 1985; Marcilly, 2003) and involves a limited number of elementary steps. Nevertheless, the number of reactions and species is in most cases still too high to perform a direct comparison between simulated and experimental data. Hence, a representative reduction of the kinetic model needs to be performed.

Reaction network reduction techniques can be divided into five categories: global reduction, response modeling, chemical lumping, statistical lumping and detailed reduction (Frenklach, 1987). The aim of a rigorous reduction technique is to retain as much as possible the detail of the original reaction network. When the kinetic equations between species are known and sets of species are in thermochemical equilibrium, one can group the species in equilibrium into lumps and write a new reduced kinetic network between lumps that is exactly equivalent to the original network. In this sense, this is strictly an exact lumping technique as defined by Wei and Kuo (1969), since the composition of each lump is known through the equilibrium relations. Hence, when experimental data shows that the species of a lump are in thermochemical equilibrium, the proposed a posteriori lumping scheme groups species at thermodynamic equilibrium inside a single lump. It is therefore a rigorous network reduction technique that allows to obtain a simplified network, which can then be used in reactor simulations (Vynckier and Froment, 1991). Indeed, using such a rigorous network reduction method avoids the problems related to the diversity of feedstocks, unlike a priori relumping of species, which is generally a "blind" lumping approach devised to cope with the lack of component-based analytical data and where empirical kinetics do not account for the composition of the lumps.

In this paper, the above-described a posteriori lumping method is applied to the catalytic reforming of hydrocarbons.

\section{NETWORK GENERATION}

The general approach for the semi-formal network generation algorithm is to rely on a detailed mechanism for the reactions occurring on the surface of the catalyst and to account for the presence of each species. The elementary steps occurring on the catalyst surface obviously depend on the process being modeled and the catalyst being used. Hence, one first needs to define the reaction mechanisms for the various chemical transformations occurring during the catalytic reforming over a bifunctional metal-acid catalyst.

Investigating the skeletal isomerization of alkanes (Sinfelt et al., 1960; Ciapetta, 1961; Sterba and Haensel, 1976) and cycloalkanes (Sterba and Haensel, 1976), several research groups showed that, for bifunctional catalysts with more than $0.1 \mathrm{wt} \%$ of platinum, the isomerization of alkanes and cycloalkanes can no longer be increased by increasing the 
platinum content. For high platinum contents, the isomerization rate significantly increases with increasing halogen content, indicating that the reaction rate is limited by the acidity of the catalyst. Hence, the metal-catalyzed skeletal isomerization does not contribute appreciably to the overall isomerization reaction on a bifunctional catalyst (Burch and Garla, 1981; Sinfelt, 1981; Maire and Garin, 1984). The above results therefore clearly illustrate that, for industrial catalysts, the rate determining step in the isomerization of paraffins and naphthenes is located on the acid sites.

In contrast to the results observed for the skeletal isomerization of paraffins and naphthenes, the rate of ring closure of alkanes on a bifunctional $\mathrm{Pt} / \mathrm{Al}_{2} \mathrm{O}_{3}$ catalyst increases significantly with increasing platinum loadings (Sinfelt et al., 1962). The increase in reaction rate was less than proportional to the increase in platinum content, however. Since the cyclization rate also depends on the acidity of the catalyst (Ciapetta and Wallace, 1971), several reaction pathways are probably in competition. According to Gates et al. (1979), the literature data seems to suggest that the acid-catalyzed and the metal-catalyzed cyclization routes may be of similar importance. Davis (1999) states, however, that for naphtha reforming catalysts, a bifunctional pathway with cyclization proceeding on the acid site is more rapid than the monofunctional metal-catalyzed cyclization pathway. Although a number of contradicting observations still exist in the literature for the cyclization of paraffins into naphthenes, it is generally accepted that, for industrial bifunctional reforming catalysts, the largest contribution for the skeletal rearrangements takes place on the acid phase (Sinfelt, 1997; Martino, 1998; Marcilly, 2003).

When modeling catalytic reforming over bifunctional metal-acid catalyst (Kmak, 1971, 1973; Ramage et al., 1980, 1987; Marin and Froment, 1982, 1990; Marin et al., 1983; Schipper et al., 1984; Van Trimpont et al., 1985, 1986a, b, 1988; Sapre, 1991; Verstraete, 1997; Joshi et al., 1999; Ancheyta-Juárez et al., 2001; Klein et al., 2006; Wei et al., 2008; Sotelo-Boyás and Froment, 2009), the mechanism proposed by Mills et al. (1953) is commonly retained, as it has been proven able to provide a good description of the process, even though it minimizes the role of the metal function. This mechanism is schematically illustrated in Figure 1. The hydrocarbons are first adsorbed and then dehydrogenated on the metal phase. The corresponding olefins desorb and then react with the acid phase to form adsorbed carbocations. The latter then undergo molecular rearrangements. The carbocations can then desorb through deprotonation into olefins, which will, after hydrogenation on a metal site, produce saturated hydrocarbons.

Writing a detailed network involves listing all types of elementary reactions that may occur. The chemistry of carbocations involved in acid-catalyzed reactions has been extensively studied and documented in the literature (Brouwer, 1980; Olah et al., 1985), and an excellent overview is given

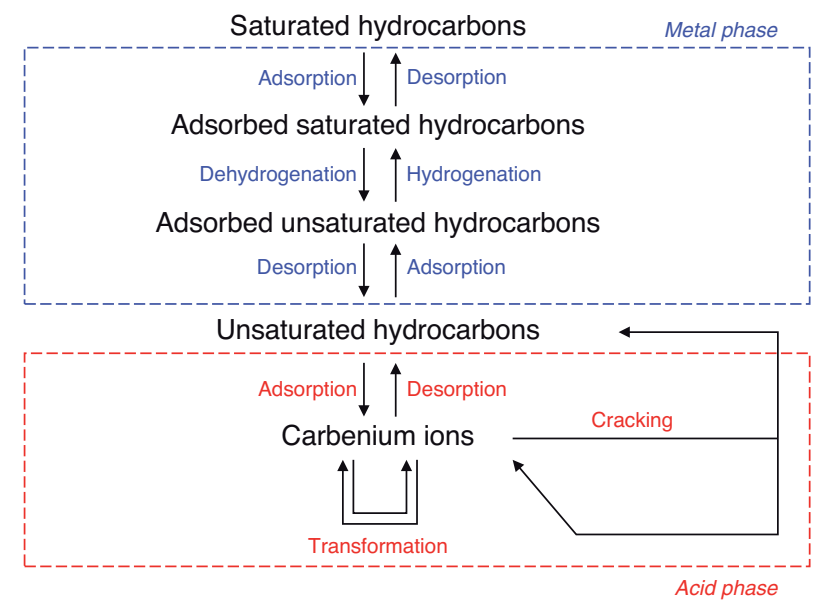

Figure 1

Reaction mechanism of the kinetic model for catalytic reforming.

by Marcilly (2003). Carbenium ion chemistry allows to draw up a list of the elementary reactions occurring on the acid surface as a function of the species involved. The reactions can therefore be classified according to the type of molecule that is reacting. One can identify:

- protonation $(P r)$ and deprotonation $(D e)$ reactions;

- isomerizations with no change in the number of branches: Hydride Shift (HS), Methyl Shift (MS), Ethyl Shift (ES), etc.;

- isomerizations with a change in the number of branches: PCP branching $(P C P)$, etc.;

- bond ruptures: acyclic beta-scission (acyc), endocyclic beta scission (endo), exocyclic beta scission (exo), etc.

The main acid-catalyzed reactions for the various types of carbenium ions are illustrated in Figure 2. Concerning the exocyclic $\beta$-scission steps, two different cases are distinguished, one in which the leaving group is an acyclic olefin $($ exoO), and a second type in which a cyclic olefin is the leaving group $(\mathrm{exoN})$.

Besides acid-catalyzed reactions, metal-catalyzed reactions have to be accounted for when modeling catalytic reforming. Here, one can identify the following set of reactions:

- dehydrogenation $(D H)$ and hydrogenation $(H y d)$ reactions; - hydrogenolysis reactions, mainly demethylation $(D M)$ and deethylation $(D E)$ on Pt-based catalysts.

As described above, the amount of platinum on catalytic reforming catalysts is generally sufficiently high to maintain the hydrogenation/dehydrogenation reactions at equilibrium. For the hydrogenolysis reactions, the same approach as for acid-catalyzed reactions could be followed. However, the chemistry of hydrogenolysis reactions and the nature of the intermediates involved in these metal-catalyzed reactions are 
Saturated acyclic carbenium ions

Protonation / Deprotonation

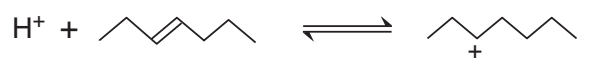

Hydride shift

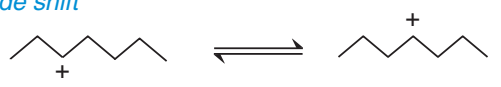

Methyl shift<smiles>CCCCCC(C)CCCC</smiles>

Ethyl shift
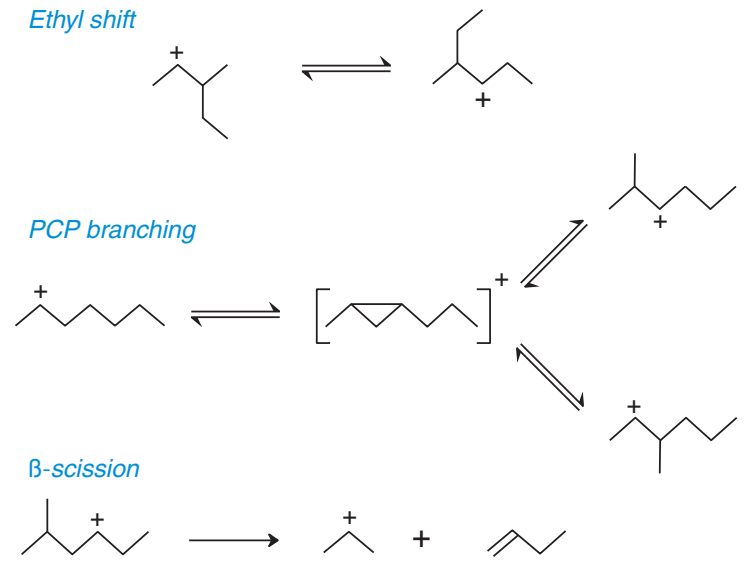

Unsaturated acyclic carbenium ions

Protonation / Deprotonation

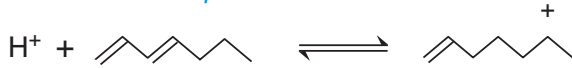

Cyclization / Endocyclic B-scission

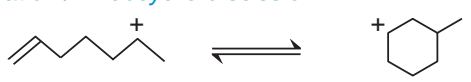

Saturated cyclic carbenium ions

$\mathrm{H}^{+}+$<smiles>C1=CCCCCC1</smiles>

$\rightleftharpoons$

Hydride shift

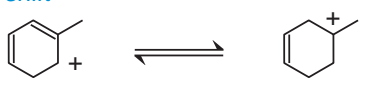

Methyl shift

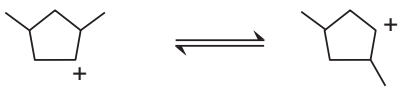

Ethyl shift

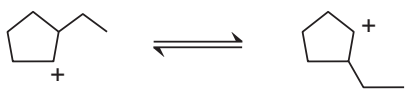

Endocyclic IntraRing Alkyl shift

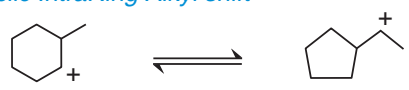

PCP branching

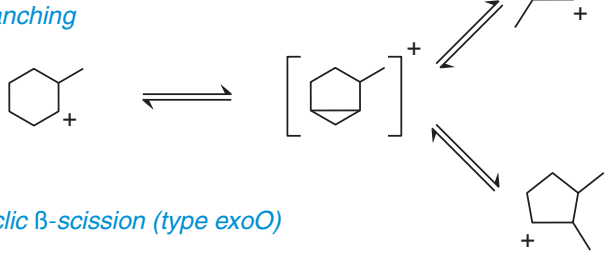

Endocyclic B-scission (type exoO)

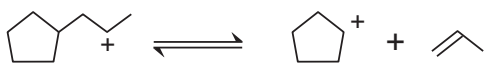

Endocyclic B-scission (type exoN)

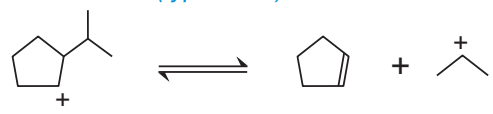

Unsaturated cyclic carbenium ions

Protonation/deprotonation

$\mathrm{H}^{+}+\overbrace{}^{+}$

Figure 2

Elementary steps between carbenium ions occurring of the acid phase of the catalyst.

still subject to much discussion. Hence, both for the hydrogenation/dehydrogenation reactions and the hydrogenolysis reactions, the reaction will only be generated on a molecular level, without explicitly accounting for the intermediates on the metal phase.

By way of example, the semi-formal network generation will be illustrated for isomerization of a pure $n$-hexane feedstock on a bifunctional catalyst. Applying the abovedescribed hydrogenation/dehydrogenation and hydrogenolysis reactions the metal phase and the carbocation chemistry to the species adsorbed on the acid phase, one can write the reaction network for catalytic reforming of $n$-hexane shown in Figure 3 by starting from $n$-hexane, or any other of the $\mathrm{C}_{6}$ components. To allow depicting the network in a single drawing, the hydrogenolysis reactions have been omitted from Figure 3.

As can be seen, the catalytic reforming reaction network for $n$-hexane already contains a large number of species (reactants, intermediates and products) and many different types of reactions. For components with more than 7 carbon 


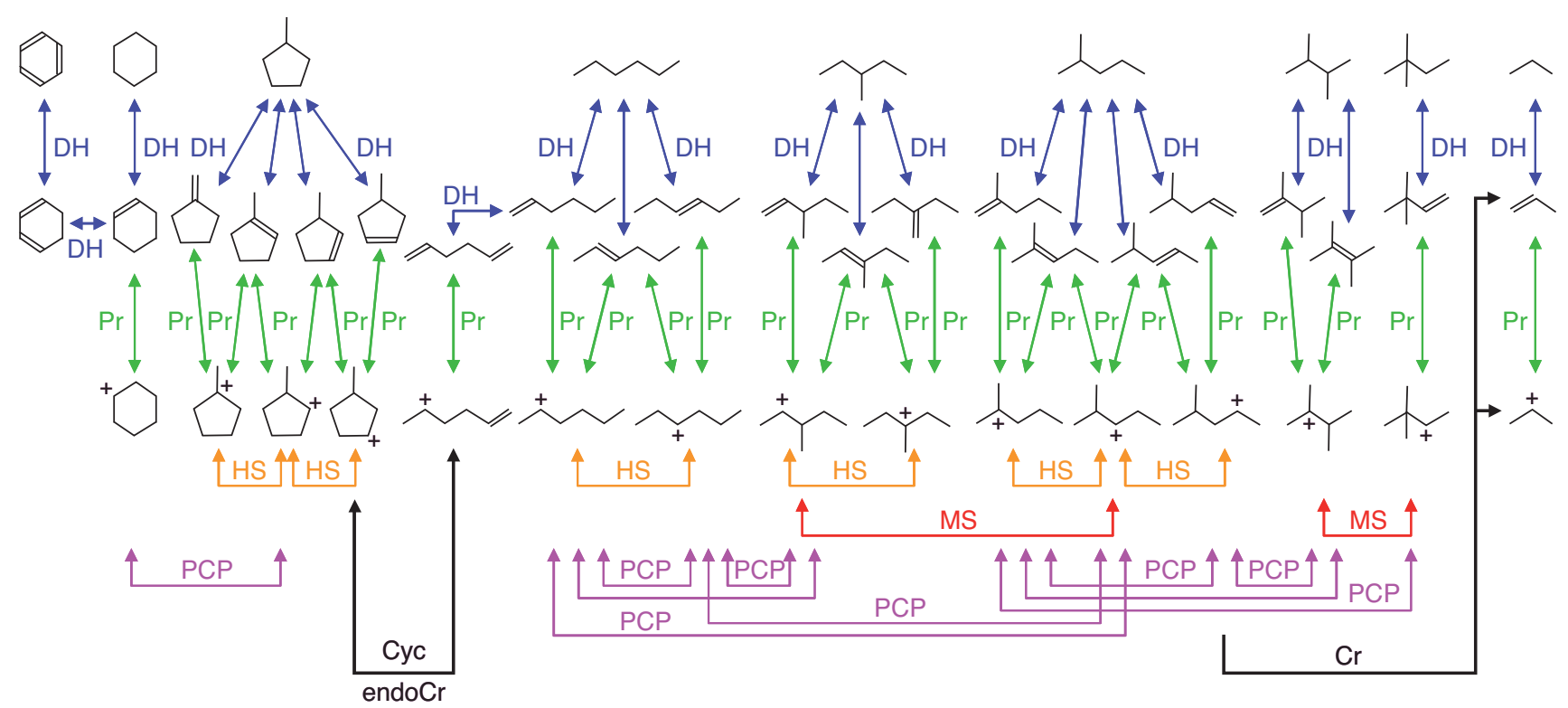

Figure 3

Reaction network for the catalytic reforming of $n$-hexane (without hydrogenolysis reactions).

atoms, writing complete mechanisms becomes tedious due to the nearly exponential increase in the size of the reaction networks. Hence, computer programs are needed to automatically generate the full-scale reaction networks.

The network generation algorithm used in single events modeling has been extensively described in detail in the literature (Clymans and Froment, 1984; Baltanas and Froment, 1985; Baltanas et al., 1989; Vynckier et Froment, 1991; Svoboda et al., 1995; Lozano et al., 2006, 2008; SoteloBoyás and Froment, 2009; Surla et al., 2011).

In the case of catalytic reforming, reaction networks involving components with up to 11 carbon atoms (when using real feedstocks) can be generated. In the study described here, a reaction network will be generated limited to species with 7 carbon atoms or less (model feedstocks). In this case, the reaction network then consists of a large number of molecules and reactions, as shown in Table 1 .

\section{KINETICS OF ELEMENTARY REACTIONS}

The previous section detailed the semi-formal computer generation of a detailed reaction network, in other words the exhaustive list of species involved and the reactions between them. To predict the evolution of a population of molecules, the rate of each reaction must be quantified.
The reaction steps generated for the acid phase are assumed to be elementary. Hence, the kinetics of each step follow the mass action law, are therefore in this case first order with respect to the reactants. This leads to the following expressions for the protonation reactions $(P r)$, surface reactions (reac), and deprotonation reactions $(D e)$ :

$$
\begin{gathered}
r_{P r}=k_{P r} \cdot C_{H^{+}} \cdot C_{O_{i j}} \\
r_{\text {reac }}=k_{\text {reac }} \cdot C_{R_{m}^{+}} \\
r_{D e}=k_{D e} \cdot C_{R_{m}^{+}}
\end{gathered}
$$

The number of kinetic parameters associated with the reactions also becomes very high and it is unreasonable to consider keeping as many degrees of freedom as there are reactions. Using the single-events concept allows to significantly limit the number of independent kinetic parameters. The principles of single-events modeling will be briefly outlined. For further details, the reader is referred to the extensive literature on single events modeling (Baltanas and Froment, 1985; Baltanas et al., 1989; Vynckier and Froment, 1991; Feng et al., 1993; Svoboda et al., 1995; Dewachtere et al. 1999; Froment, 1999; Martens et al., 2001; Thybaut and Marin, 2003; Moustafa and Froment, 2003; Park and Froment, 2004; Laxmi Narasimhan et al., 2004; Froment, 2005; Martinis and Froment, 2006; Lozano et al., 2006; Kumar and Froment, 2007a, b; Lozano et al., 2008; Mitsios et al., 2009; Surla et al., 2011). 
TABLE 1

Reaction network generated for model components with up to 7 carbon atoms

\begin{tabular}{|c|c|c|}
\hline Components & Metal phase reactions & Acid phase reactions \\
\hline $\begin{array}{l}\text { Main components } \\
22 \text { paraffins } \\
8 \text { naphthenes } \\
2 \text { aromatics } \\
\text { Olefins } \\
50 \text { acyclic olefins } \\
25 \text { cyclic olefins } \\
46 \text { acyclic diolefins } \\
38 \text { cyclic diolefins } \\
\text { Carbenium ions } \\
38 \text { carbenium ions } \\
21 \text { cyclic carbenium ions } \\
7 \text { olefinic carbenium ions } \\
0 \text { cyclic olefinic carbenium ions }\end{array}$ & 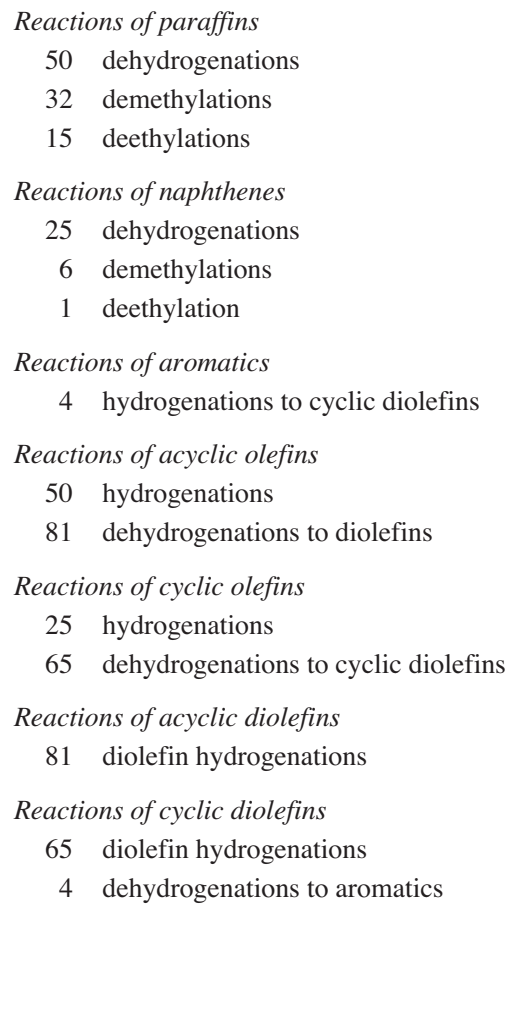 & 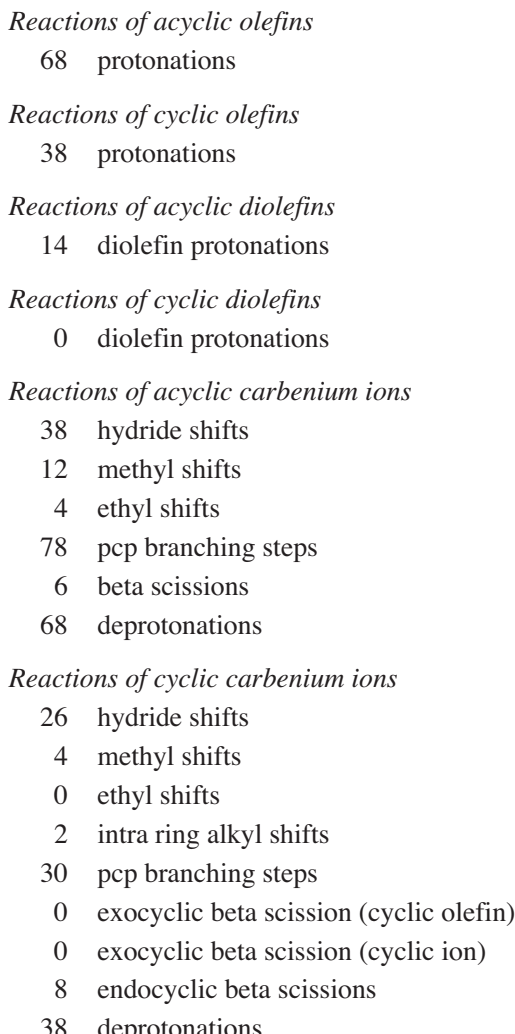 \\
\hline
\end{tabular}

From transition state theory, the rate coefficient of an elementary reaction can be written according to Eyring's law:

$$
k=\frac{k_{B} T}{h} \cdot \exp \left(\frac{\Delta S^{\text {o\# }}}{R}\right) \cdot \exp \left(-\frac{\Delta H^{\text {o\# }}}{R T}\right)
$$

where $k$ is the rate coefficient of an elementary step,

$k_{B} \quad$ is Boltzmann's constant,

$h$ is Planck's constant,

$R \quad$ is the ideal gas constant,

$T \quad$ is the temperature,

$\Delta S^{\text {o\# }}$ is the activation entropy,

$\Delta H^{\text {o\# }}$ is the activation enthalpy.

The standard entropy $S^{\circ}$ of the reactant and the transition state can be split into several contributions. For the reactions in the network, the translational, vibrational and electronic contributions are considered to be the same, but the rotational contributions strongly depend on the symmetry of the molecule (Willems and Froment, 1988a). If the molecule is optically active, the standard entropy must also be corrected by adding an asymmetry term related to its chirality. The entropy contributions due to the symmetry of the molecule and to its chirality can be set apart accounting respectively for the symmetry number $\sigma$ of the compound and the number of diastereo-isomers (Benson et al., 1969; Benson, 1976), and the remainder is called the intrinsic standard entropy $\widetilde{S}^{\circ}$ :

$$
k=\frac{k_{B} T}{h} \cdot\left(\frac{\sigma_{r}}{\sigma_{\#}}\right) \cdot \exp \left(\frac{\Delta \tilde{S}^{\text {o\# }}}{R}\right) \cdot \exp \left(-\frac{\Delta H^{\text {o\# }}}{R T}\right)
$$

where $\Delta \widetilde{S}^{\text {o\# }}$ is the intrinsic activation entropy,

$\sigma_{r}$ is the global symmetry number of the reactant,

$\sigma_{\#}$ is the global symmetry number of the activated complex.

This equation can be rewritten as:

$$
k=n_{e} \cdot \tilde{k}
$$

with:

$$
\begin{gathered}
n_{e}=\frac{\sigma_{r}}{\sigma_{\#}} \\
\tilde{k}=\frac{k_{B} T}{h} \cdot \exp \left(\frac{\Delta \tilde{S}^{\text {\# }}}{R}\right) \cdot \exp \left(-\frac{\Delta H^{\text {o\# }}}{R T}\right)
\end{gathered}
$$


where $n_{e}$ is the number of single events,

$\widetilde{k}$ is the fundamental rate coefficient of an acidcatalyzed single event.

The ratio of the global symmetry number of the reactant divided by the global symmetry number of the activated complex is by definition the number of single events. It is related to the number of identifiable pathways corresponding to an elementary reaction (Baltanas and Froment, 1985; Vynckier et Froment, 1991). The generation algorithm includes the procedures to calculate these symmetries. The number of single-events is thus stored together with the description of a reaction. In view of energy considerations on the reactants, one can reasonably assume that the fundamental rate coefficient $\widetilde{k}$ depends only on the type of reaction and the nature of the ions involved, and does not depend on the number of carbon atoms (Baltanas and Froment, 1985; Vynckier et Froment, 1991; Surla et al., 2011). Consequently, the number of kinetic constants needed to describe the system is limited. In addition, thermodynamic constraints on the reversible reactions reduce the number of parameters even further (Baltanas and Froment, 1985; Vynckier et Froment, 1991; Surla et al., 2011). Finally, only the following fundamental rate parameters are required to model the catalytic reforming kinetics:

- isomerization: $\tilde{k}_{i s o}(s, s), \widetilde{k}_{i s o}(s, t), \tilde{k}_{i s o}(t, t)$;

- cyclization: $\widetilde{k}_{c y c}(s, s), \widetilde{k}_{c y c}(s, t), \widetilde{k}_{c y c}(t, t)$;

- exocyclic cracking exoO: $\tilde{k}_{\text {exoO }}(s, s), \widetilde{k}_{\text {exoO }}(s, t), \tilde{k}_{\text {exoO }}(t, s)$, $\widetilde{k}_{\text {exoO }}(t, t)$;

- exocyclic cracking exoN: $\tilde{k}_{\text {exoN }}(s, s), \tilde{k}_{\text {exoN }}(s, t), \widetilde{k}_{\text {exo } N}(t, s)$, $\tilde{k}_{\text {exoN }}(t, t)$.

The reaction steps generated for the metal phase are stored as molecular pathways. As the hydrogenation/dehydrogenation reactions are considered to be at equilibrium, their kinetics do not have to be detailed. For the hydrogenolysis reactions, however, a rate equation needs to be proposed. As hydrogenolysis is generally considered to proceed through dehydrogenated intermediates (Verstraete, 1997), a bimolecular carbon-carbon scission of an absorbed intermediate is retained. For a paraffin $P_{i}$, this leads to the following rate equations:

$$
\begin{aligned}
& r_{D M}=k_{D M} \cdot P_{P_{i}} \cdot P_{\mathrm{H}_{2}}^{1-a} \cdot C_{M}^{2} \\
& r_{D E}=k_{D E} \cdot P_{P_{i}} \cdot P_{\mathrm{H}_{2}}^{1-a} \cdot C_{M}^{2}
\end{aligned}
$$

where $r_{D M}$

is the rate of demethylation,

$r_{D E}$

$k_{D M}$ is the rate of deethylation,

$k_{D E}$

is the rate coefficient for demethylation,

$p_{p_{i}}$ is the rate coefficient for deethylation,

$p_{\mathrm{H}_{2}} \quad$ is the partial pressure of hydrogen,

$a$ is the degree of unsaturation of the adsorbed intermediate,

$C_{M} \quad$ is the concentration of free metal sites.
Again, as the number of kinetic parameters associated with hydrogenolysis reactions also becomes very high, it is unreasonable to keep a separate rate coefficient for each reaction. In analogy to the single-events concept, the rate coefficient is therefore split into a more fundamental parameter $\bar{k}$ and the number of reaction pathways $n_{s}$ between reactant and product (Verstraete, 1997):

$$
k=n_{s} \cdot \bar{k}
$$

In this approach, the number of reaction pathways $n_{s}$ is equal to the number of identifiable pathways corresponding to the global hydrogenolysis reaction, and is determined during the automated reaction network generation.

\section{A POSTERIORI RELUMPING OF SPECIES: THE CASE OF CATALYTIC REFORMING}

\subsection{Families Considered}

Comparing experimental data obtained on various feedstocks and at various contact times to thermodynamic equilibrium calculations have demonstrated that the paraffins with the same of carbon atoms and the same number of branches are in equilibrium with each other (Verstraete, 1997; Cochegrue, 2001; Gauthier, 2004). From these data, it can be concluded that isomerization reactions with no change in the number of branches (HS, MS, ES) are very fast compared with isomerization reactions with a change in the number of branches (PCP), cracking reactions and cyclization reactions. Cyclic compounds with the same number of carbon atoms and the same number of branches are also in equilibrium with each other: ring contraction or expansion reactions as well as dehydrogenation of naphthenes into aromatics are very fast compared to branching isomerization reactions (Verstraete, 1997).

The adopted relumping strategy is therefore as follows:

- Acyclic compounds: four families are considered for each carbon number:

- nP: linear paraffins,

- moP: monobranched paraffins,

- diP: dibranched paraffins,

- triP: tribranched paraffins.

- Monocyclic compounds: five families are considered for each carbon number:

- nN: unsubstituted naphthenes and aromatics,

- moN: monobranched naphthenes and aromatics,

- diN: dibranched naphthenes and aromatics,

- triN: tribranched naphthenes and aromatics,

- teN: tetrabranched naphthenes and aromatics.

- Dicyclic compounds: four families are considered for each carbon number:

- nDN: unsubstituted dinaphthenes, naphthenoaromatics and diaromatics, 
- moDN: monobranched dinaphthenes, naphthenoaromatics and diaromatics,

- diDN: dibranched dinaphthenes, naphthenoaromatics and diaromatics,

- triDN: tribranched dinaphthenes, naphthenoaromatics and diaromatics.

Tetrabranched paraffins are not considered since they are present neither in the feedstocks nor in the effluents. Hence, generation of such species has been forbidden during network generation. To allow the paring reaction on cycloalkanes (Sullivan et al., 1961; Weitkamp et al., 1984; Souverijns et al., 1996), tetrabranched naphthenes and aromatics were included in the network, however. This $a$ posteriori relumping allows reducing drastically the number of species to follow during the simulations. Indeed, as the species within each lump are in equilibrium, they do not need to be followed in detail. Table 2 illustrates the reduction in

TABLE 2

Reduction in reaction network size obtained through a posteriori relumping

\begin{tabular}{c|r|r|r|r}
\hline $\begin{array}{c}\text { Reaction } \\
\text { network }\end{array}$ & \multicolumn{2}{|c|}{$\begin{array}{c}\text { Before } \\
\text { relumping }\end{array}$} & \multicolumn{2}{c}{$\begin{array}{c}\text { After } \\
\text { relumping }\end{array}$} \\
\hline $\begin{array}{c}\text { Number } \\
\text { of carbon } \\
\text { atoms }\end{array}$ & $\begin{array}{c}\text { Number } \\
\text { of species }\end{array}$ & $\begin{array}{c}\text { Number } \\
\text { of steps }\end{array}$ & $\begin{array}{c}\text { Number } \\
\text { of lumps }\end{array}$ & $\begin{array}{c}\text { Number } \\
\text { of reactions }\end{array}$ \\
\hline 6 & 91 & 278 & 15 & 27 \\
\hline 7 & 258 & 964 & 22 & 57 \\
\hline 8 & 795 & 3374 & 32 & 108 \\
\hline 9 & 2501 & 11509 & 46 & 191 \\
\hline 10 & 7915 & 37853 & 64 & 308 \\
\hline 11 & 24120 & 117195 & 82 & 462 \\
\hline
\end{tabular}

TABLE 3

Importance of the various types of reactions in the a posteriori relumped reaction networks

\begin{tabular}{l|r|r|r|r|r|r}
\hline Reaction network & 6 & 7 & 8 & 9 & 10 & 11 \\
\hline Isomerization & 4 & 8 & 13 & 20 & 28 & 36 \\
\hline Acyclic $\beta$-scission & 1 & 6 & 18 & 39 & 69 & 108 \\
\hline Exocyclic $\beta$-scission exoN & 0 & 0 & 1 & 6 & 18 & 40 \\
\hline Exocyclic $\beta$-scission exoO & 0 & 0 & 1 & 6 & 18 & 41 \\
\hline Endocyclic $\beta$-scission & 1 & 4 & 10 & 20 & 32 & 45 \\
\hline Cyclization & 1 & 4 & 10 & 20 & 32 & 45 \\
\hline DeMethylation & 13 & 22 & 33 & 47 & 64 & 83 \\
\hline DeEthylation & 7 & 13 & 22 & 33 & 47 & 64 \\
\hline Total & 27 & 57 & 108 & 191 & 308 & 462 \\
\hline
\end{tabular}

problem size of the kinetic model. The $\mathrm{C}_{7}$ network for catalytic reforming is therefore reduced to 22 lumps instead of the initial 32 observable components and to 57 reactions instead of the 216 acid-phase rate determining elementary reactions (after considering that the hydrogenation/ dehydrogenation steps, the protonation/deprotonation steps and the hydride shifts are in equilibrium) and the 54 catalyzed hydrogenolysis reactions. Table 3 lists the various types of reactions that are present in the a posteriori relumped reaction networks.

\subsection{Calculation of the Rates of the Acid-catalyzed Reactions between Lumps}

The rates of reaction between two lumps $L_{1}$ and $L_{2}$ are equal to the sums of all reactions between elements in each lump. Sub-sums can be calculated for each type of reaction. One therefore obtains the following rates of reaction between lumps:

- isomerization:

$$
\begin{aligned}
R_{i s o}\left(L_{1}\right. & \left.\Leftrightarrow L_{2}\right)=\sum_{z} n_{e, i s o}(z) \cdot \tilde{k}_{i s o}(m, n) \cdot C_{R_{m}^{+}}^{L_{1}} \\
& -\sum_{z^{\prime}} n_{e, i s o}\left(z^{\prime}\right) \cdot \tilde{k}_{i s o}(n, m) \cdot C_{R_{n}^{+}}^{L_{2}}
\end{aligned}
$$

- cyclization:

$$
\begin{aligned}
R_{c y c}\left(L_{1}\right. & \left.\Leftrightarrow L_{2}\right)=\sum_{z} n_{e, c y c}(z) \cdot \tilde{k}_{c y c}(m, n) \cdot C_{O R_{m}^{+}}^{L_{1}} \\
& -\sum_{z^{\prime}} n_{e, \text { endo }}\left(z^{\prime}\right) \cdot \tilde{k}_{\text {endo }}(n, m) \cdot C_{N R_{n}^{+}}^{L_{2}}
\end{aligned}
$$

- acyclic cracking:

$$
R_{\text {acyc }}\left(L_{1} \rightarrow L_{2}+L_{3}\right)=\sum_{z} n_{e, a c y c}(z) \cdot \tilde{k}_{\text {acyc }}(m ; n, O) \cdot C_{R_{m}^{+}}^{L_{1}}
$$

- exocyclic cracking of type exoN:

$$
R_{\text {exoN }}\left(L_{1} \rightarrow L_{2}+L_{3}\right)=\sum_{z} n_{e, e x o N}(z) \cdot \tilde{k}_{\text {exoN }}(m ; n, N O) \cdot C_{N R_{m}^{+}}^{L_{1}}
$$

- exocyclic cracking of type exoO:

$$
R_{\text {eхоO }}\left(L_{1} \rightarrow L_{2}+L_{3}\right)=\sum_{z} n_{\text {eеххо }}(z) \cdot \tilde{k}_{\text {eхоO }}(m ; n, O) \cdot C_{N R_{m}^{+}}^{L_{1}}
$$

with $z$ a reaction between carbenium ion $m$ belonging to $L_{1}$ and carbenium ion $n$ belonging to $L_{2}$ (and olefin $\mathrm{O}$ (or $\mathrm{NO}$ ) belonging to $L_{3}$ ).

\subsubsection{Expressions for the Carbenium Ion Concentrations}

The balance on the acid sites leads to the following equation:

$$
C_{t o t, H^{+}}=C_{H^{+}}+\sum_{m} C_{R_{m}^{+}}+\sum_{n} C_{O R_{n}^{+}}+\sum_{o} C_{N R_{o}^{+}}+\sum_{q} C_{N O R_{q}^{+}}+\sum_{r} C_{D N R_{r}^{+}}
$$


If protonation and deprotonation are very fast in comparison to the other transformations, the carbenium ion concentrations can be determined very easily by using the assumption of equilibrium of the protonation and deprotonation reactions between the olefins in the gas phase and the ions adsorbed on the catalyst (Vynckier and Froment, 1991):

$$
\begin{gathered}
C_{R_{m}^{+}}=\frac{k_{P r}(m)}{k_{D e}\left(m ; O_{i j}\right)} \cdot p_{O_{i j}} \cdot C_{H^{+}} \\
C_{O R_{n}^{+}}=\frac{k_{P r}^{\prime}(m)}{k_{D e}\left(m ; D O_{i k}\right)} \cdot p_{D O_{i k}} \cdot C_{H^{+}} \\
C_{N R_{O}^{+}}=\frac{k_{P r}(m)}{k_{D e}\left(m ; N O_{i j}\right)} \cdot p_{N O_{i j}} \cdot C_{H^{+}} \\
C_{N O R_{q}^{+}}=\frac{k_{P r}^{\prime}(m)}{k_{D e}\left(m ; N D O_{i k}\right)} \cdot p_{N D O_{i k}} \cdot C_{H^{+}} \\
C_{D N R_{r}^{+}}=\frac{k_{P r}(m)}{k_{D e}\left(m ; D N O_{i j}\right)} \cdot p_{D N O_{i j}} \cdot C_{H^{+}}
\end{gathered}
$$

Due to the hydrogenation/dehydrogenation equilibrium on the metal phase, the partial pressures of the unsaturated species can be directly related to the corresponding saturated species:

$$
\begin{gathered}
C_{R_{m}^{+}}=\frac{k_{P r}(m)}{k_{D e}\left(m ; O_{i j}\right)} \cdot K\left[P_{i} \Leftrightarrow O_{i j}+\mathrm{H}_{2}\right] \cdot \frac{p_{P_{i}}}{p_{\mathrm{H}_{2}}} \cdot C_{H^{+}} \\
C_{O R_{n}^{+}}=\frac{k_{P r}^{\prime}(m)}{k_{D e}\left(m ; D O_{i k}\right)} \cdot K\left[P_{i} \Leftrightarrow D O_{i k}+2 \mathrm{H}_{2}\right] \cdot \frac{p_{P_{i}}}{p_{\mathrm{H}_{2}}{ }^{2}} \cdot C_{H^{+}} \\
C_{N R_{o}^{+}}=\frac{k_{P r}(m)}{k_{D e}\left(m ; N O_{i j}\right)} \cdot K\left[N_{i} \Leftrightarrow N O_{i j}+\mathrm{H}_{2}\right] \cdot \frac{p_{N_{i}}}{p_{\mathrm{H}_{2}}} \cdot C_{H^{+}} \\
C_{N O R_{q}^{+}}=\frac{k_{P r}^{\prime}(m)}{k_{D e}\left(m ; N D O_{i k}\right)} \cdot K\left[N_{i} \Leftrightarrow N D O_{i k}+2 \mathrm{H}_{2}\right] \cdot \frac{p_{N_{i}}}{p_{\mathrm{H}_{2}}^{2}} \cdot C_{H^{+}} \\
C_{D N R_{r}^{+}}=\frac{k_{P r}(m)}{k_{D e}\left(m ; D N O_{i j}\right)} \cdot K\left[D N_{i} \Leftrightarrow D N O_{i j}+\mathrm{H}_{2}\right] \cdot \frac{p_{D N_{i}}}{p_{\mathrm{H}_{2}}} \cdot C_{H^{+}}
\end{gathered}
$$

The concentration of free acid sites is then deduced from the previous relations:

$$
C_{H^{+}}=\frac{C_{t o t, H^{+}}}{D E N_{A}}
$$

with:

$$
\begin{aligned}
D E N_{A} & =1+\sum_{\{a\}} \frac{k_{P r}(m)}{k_{D e}\left(m ; O_{i j}\right)} \cdot K\left[P_{i} \leftrightarrow O_{i j}+\mathrm{H}_{2}\right] \cdot \frac{p_{P_{i}}}{p_{\mathrm{H}_{2}}} \\
& +\sum_{\{b\}} \frac{k_{P r}^{\prime}(m)}{k_{D e}\left(m ; D O_{i k}\right)} \cdot K\left[P_{i} \leftrightarrow D O_{i k}+2 \mathrm{H}_{2}\right] \cdot \frac{p_{P_{i}}}{p_{\mathrm{H}_{2}}^{2}} \\
& +\sum_{\{c\}} \frac{k_{P r}(m)}{k_{D e}\left(m ; N O_{i j}\right)} \cdot K\left[N_{i} \leftrightarrow N O_{i j}+\mathrm{H}_{2}\right] \cdot \frac{p_{N_{i}}}{p_{\mathrm{H}_{2}}} \\
& +\sum_{\{d\}} \frac{k_{P r}^{\prime}(m)}{k_{D e}\left(m ; N D O_{i k}\right)} \cdot K\left[N_{i} \leftrightarrow N D O_{i k}+2 \mathrm{H}_{2}\right] \cdot \frac{p_{N_{i}}}{p_{\mathrm{H}_{2}}^{2}} \\
& +\sum_{\{e\}} \frac{k_{P r}(m)}{k_{D e}\left(m ; D N O_{i j}\right)} \cdot K\left[D N_{i} \leftrightarrow D N O_{i j}+\mathrm{H}_{2}\right] \cdot \frac{p_{D N_{i}}}{p_{\mathrm{H}_{2}}}
\end{aligned}
$$

where $\{a\}$ is the set of all acyclic saturated ions present on the acid phase,

$\{b\}$ is the set of all acyclic unsaturated ions present on the acid phase,

$\{c\}$ is the set of all cyclic saturated ions present on the acid phase,

$\{d\}$ is the set of all cyclic unsaturated ions present on the acid phase,

$\{e\}$ is the set of all dicyclic unsaturated ions present on the acid phase.

Consequently, the concentrations of the acyclic saturated carbenium ions are given by:

$$
C_{R_{m}^{+}}=\frac{\frac{k_{P r}(m)}{k_{D e}\left(m ; O_{i j}\right)} \cdot K\left[P_{i} \Leftrightarrow O_{i j}+\mathrm{H}_{2}\right] \cdot \frac{p_{P_{i}}}{p_{\mathrm{H}_{2}}} \cdot C_{t o t, H^{+}}}{D E N_{A}}
$$

To reduce the number of parameters, the fundamental single event rate coefficients should be introduced by isolating the number of single events for the protonation and deprotonation steps. Moreover, the single event rate coefficient for deprotonation is given for a reference olefin $O_{r}$. Using the thermodynamic constraints on the deprotonation constants of the carbenium ions (Baltanas and Froment, 1985; Vynckier et Froment, 1991; Surla et al., 2011), one obtains the following expression for the concentrations of the acyclic saturated carbenium ions:

$$
C_{R_{m}^{+}}=\frac{\frac{n_{e, P r}(m)}{n_{e, D e}\left(m, O_{i j}\right)} \cdot \frac{\tilde{k}_{P r}(m)}{\tilde{k}_{D e}\left(m ; O_{r}\right)} \cdot \frac{1}{\tilde{K}\left[o_{r} \Leftrightarrow O_{i j}\right]} \cdot K\left[{ }_{P_{i} \leftrightarrow O_{i j}+\mathrm{H}_{2}}\right] \cdot \frac{p_{P_{i}}}{p_{\mathrm{H}_{2}}} \cdot C_{t o t, H^{+}}}{D E N_{A}}
$$

with $\widetilde{K}\left[o_{r} \Leftrightarrow O_{i j}\right]$ the intrinsic thermodynamic equilibrium constant for olefin isomerization. 
Similar expressions are of course obtained for the other types of carbenium ions. For example, for the concentrations of the acyclic unsaturated carbenium ions, one finds:

$$
C_{O R_{m}^{+}}=\frac{\frac{n_{e, P r}(m)}{n_{e, D e}\left(m, D O_{i k}\right)} \cdot \frac{\tilde{k}_{P_{r}}^{\prime}(m)}{\tilde{k}_{D e}\left(m ; D O_{r}\right)} \cdot \frac{1}{\tilde{K}\left[D O_{r} \Leftrightarrow D O_{i k}\right]} \cdot K\left[p_{i} \Leftrightarrow D D_{\left.i k^{2}+2 \mathrm{H}_{2}\right]}\right] \cdot \frac{p_{P_{i}}}{p_{\mathrm{H}_{2}}^{2}} \cdot C_{t o t, H^{+}}}{D E N_{A}}
$$

with $\widetilde{K}\left[D O_{r} \Leftrightarrow D O_{i k}\right]$ the intrinsic thermodynamic equilibrium constant for diolefin isomerization.

In the expressions above, the numerator and the denominator refer to the partial pressure of paraffin $P_{i}$. As the a posteriori relumped reaction network only considers the macroscopic lumps, it is desirable to refer only to the partial pressures of the lumps.

Let $L_{P}$ be the lump to which paraffin $P_{i}$ belongs. One can now define $y_{i}$ as the molar fraction of $P_{i}$ in lump $L_{P}$ as follows:

$$
y_{i}=\frac{p_{P_{i}}}{p_{L_{p}}}
$$

with $y_{i} \quad$ the molar fraction of paraffin $P_{i}$ within lump $L_{P}$,

$p_{p_{i}} \quad$ the partial pressure of paraffin $P_{i}$,

$p_{L_{P}} \quad$ the partial pressure of paraffin lump $L_{P}$ (with $\left.p_{L_{P}}=\sum_{i} p_{p_{i}}\right)$.

The concentrations of the acyclic saturated carbenium ions are therefore obtained from:

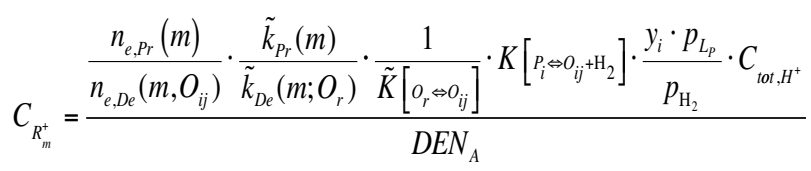

with the denominator given by:

$$
\begin{aligned}
& D E N_{A}=1+\sum_{\{a\}} \frac{k_{P r}(m)}{k_{D e}\left(m ; O_{i j}\right)} \cdot K\left[P_{i} \Leftrightarrow O_{i j}+\mathrm{H}_{2}\right] \cdot \frac{y_{i} \cdot p_{L_{P}}}{p_{\mathrm{H}_{2}}} \\
& +\sum_{\{b\}} \frac{k_{P r}^{\prime}(m)}{k_{D e}\left(m ; D O_{i k}\right)} \cdot K\left[P_{i} \Leftrightarrow D O_{i k}+2 \mathrm{H}_{2}\right] \cdot \frac{y_{i} \cdot p_{L_{P}}}{p_{\mathrm{H}_{2}}^{2}} \\
& +\sum_{\{c\}} \frac{k_{P r}(m)}{k_{D e}\left(m ; N O_{i j}\right)} \cdot K\left[N_{i} \Leftrightarrow N O_{i j}+\mathrm{H}_{2}\right] \cdot \frac{y_{i} \cdot p_{L_{N}}}{p_{\mathrm{H}_{2}}} \\
& +\sum_{\{d\}} \frac{k_{P r}(m)}{k_{D e}\left(m ; N D O_{i k}\right)} \cdot K\left[N_{i} \Leftrightarrow N D O_{i k}+2 \mathrm{H}_{2}\right] \cdot \frac{y_{i} \cdot p_{L_{N}}}{p_{\mathrm{H}_{2}}^{2}} \\
& +\sum_{\{e\}} \frac{k_{P r}(m)}{k_{D e}\left(m ; D N O_{i j}\right)} \cdot K\left[D N_{i} \Leftrightarrow D N O_{i j}+\mathrm{H}_{2}\right] \cdot \frac{y_{i} \cdot p_{L_{D N}}}{p_{\mathrm{H}_{2}}}
\end{aligned}
$$

We can now define an overall acid-phase chemisorption coefficient $K_{L_{P}}^{P}$ for the acyclic olefins belonging to paraffin lump $L_{P}$ and an overall acid-phase chemisorption coefficient $K_{L_{P}}^{P}$ for the acyclic diolefins belonging to paraffin lump $L_{P}$.

$$
K_{L_{P}}^{P}=\sum_{\{P\}} y_{i} \cdot\left(\sum_{\{m\}} \frac{n_{e, P r}(m)}{n_{e, D e}\left(m, O_{i j}\right)} \cdot \frac{\tilde{k}_{P r}(m)}{\tilde{k}_{D e}\left(m ; O_{r}\right)} \cdot \frac{1}{\tilde{K}\left[o_{r} \Leftrightarrow o_{i j}\right]} \cdot K\left[P_{i} \Leftrightarrow O_{i j}+\mathrm{H}_{2}\right]\right)
$$

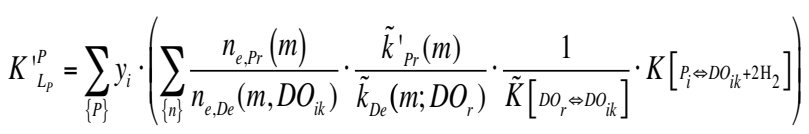

with $\{m\}$ the set of saturated ions from paraffin $P_{i}$,

$\{n\}$ the set of unsaturated ions from paraffin $P_{i}$,

$\{P\}$ the set of paraffins belonging to lump $L_{P}$.

The acid-phase chemisorption coefficient $K_{L_{P}}^{P}$ can be broken down as follows:

$$
\begin{aligned}
K_{L_{P}}^{P} & =\frac{\tilde{k}_{P_{r}}(s)}{\tilde{k}_{D e}\left(s ; O_{r}\right)} \sum_{\{P\}} \sum_{\{s\}} y_{i} \cdot \frac{n_{e, P_{r}}(s)}{n_{e, D e}\left(s, O_{i j}\right)} \cdot \frac{1}{\tilde{K}\left[o_{r} \leftrightarrow o_{i j}\right]} \cdot K\left[P_{i} \Leftrightarrow O_{i j}+\mathrm{H}_{2}\right] \\
& +\frac{\tilde{k}_{P r}(t)}{\tilde{k}_{D e}\left(t ; O_{r}\right)} \sum_{\{P\}} \sum_{\{t\}} y_{i} \cdot \frac{n_{e, P_{r}}(t)}{n_{e, D e}\left(t, O_{i j}\right)} \cdot \frac{1}{\tilde{K}\left[o_{r} \Leftrightarrow o_{i j}\right]} \cdot K\left[P_{i} \leftrightarrow O_{i j}+\mathrm{H}_{2}\right]
\end{aligned}
$$

with $\{s\}$ the set of secondary saturated ions from paraffin $P_{i}$,

$\{t\}$ the set of tertiary saturated ions from paraffin $P_{i}$,

$\{P\}$ the set of paraffins belonging to lump $L_{P}$.

$K_{L_{p}}^{P}$ has therefore two contributions, depending on the type of ion that is formed during acid-phase chemisorption:

$$
K_{L_{P}}^{P}=\frac{\tilde{k}_{P r}(s)}{\tilde{k}_{D e}\left(s ; O_{r}\right)} \cdot K C_{L_{P}}^{P}(s)+\frac{\tilde{k}_{P r}(t)}{\tilde{k}_{D e}\left(t ; O_{r}\right)} \cdot K C_{L_{P}}^{P}(t)
$$

with:

$$
\begin{aligned}
K C_{L_{P}}^{P}(s) & =\sum_{\{P\}} \sum_{\{s\}} y_{i} \cdot \frac{n_{e, P r}(s)}{n_{e, D e}\left(s, O_{i j}\right)} \cdot \frac{1}{\tilde{K}\left[o_{r} \Leftrightarrow o_{i j}\right]} \cdot K\left[P_{i} \Leftrightarrow O_{i j}+\mathrm{H}_{2}\right] \\
K C_{L_{P}}^{P}(t) & =\sum_{\{P\}} \sum_{\{t\}} y_{i} \cdot \frac{n_{e, P r}(t)}{n_{e, D e}\left(t, O_{i j}\right)} \cdot \frac{1}{\tilde{K}\left[o_{r} \Leftrightarrow o_{i j}\right]} \cdot K\left[P_{i} \Leftrightarrow O_{i j} \mathrm{H}_{2}\right]
\end{aligned}
$$

where $K C_{L_{p}}^{P}(m)$ represents a lumping coefficient for acidphase chemisorption of the various olefins linked to the paraffins $P$ from paraffinic lump $L_{P}$ and resulting in carbenium ions of type $m$.

It should be stressed that, in this expression, the factors $K C_{L_{p}}^{P}(s)$ and $K C_{L_{p}}^{P}(t)$ only depend on the generated reaction network, but not on the kinetic parameters, which have been explicitly isolated. These two factors have therefore to be calculated only once for a given reaction network. It should be stressed, however, that, for a given reaction network, this coefficient still depends on the temperature. Indeed, $y_{i}$ represents the equilibrium mole fraction of an isomer in a given lump, which evidently depends on temperature. The same holds for the dehydrogenation and olefin isomerization equilibrium constants. The advantage of isolating these terms is that, for each temperature, the lumping coefficients need to be calculated only once for a given reaction network.

Similarly, $K_{L_{p}}^{P}$ can be broken down as follows:

$$
K_{L_{P}}^{\prime P}=\frac{\tilde{k}_{P r}^{\prime}(s)}{\tilde{k}_{D e}\left(s ; D O_{r}\right)} \cdot K C_{L_{P}}^{\prime P}(s)+\frac{\tilde{k}_{P r}^{\prime}(t)}{\tilde{k}_{D e}\left(t ; D O_{r}\right)} \cdot K C_{L_{P}}^{\prime P}(t)
$$


In a similar manner, one arrives at the following expressions for the cyclic olefins, cyclic diolefins and the dicyclic olefins:

$$
\begin{aligned}
K_{L_{N}}^{N} & =\frac{\tilde{\mathrm{k}}_{P r}(s)}{\tilde{\mathrm{k}}_{D e}\left(s ; N O_{r}\right)} \cdot K C_{L_{N}}^{N}(s)+\frac{\tilde{\mathrm{k}}_{P r}(t)}{\tilde{\mathrm{k}}_{D e}\left(t ; N O_{r}\right)} \cdot K C_{L_{N}}^{N}(t) \\
K_{L_{N}}^{\prime N} & =\frac{\tilde{\mathrm{k}}_{P r}^{\prime}(s)}{\tilde{\mathrm{k}}_{D e}\left(s ; N D O_{r}\right)} \cdot K C_{L_{N}}^{\prime N}(s)+\frac{\tilde{\mathrm{k}}_{P r}^{\prime}(t)}{\tilde{\mathrm{k}}_{D e}\left(t ; N D O_{r}\right)} \cdot K C_{L_{N}}^{\prime N}(t) \\
K_{L_{D N}}^{D N} & =\frac{\tilde{\mathrm{k}}_{P r}(s)}{\tilde{\mathrm{k}}_{D e}\left(s ; D N O_{r}\right)} \cdot K C_{L_{D N}}^{D N}(s)+\frac{\tilde{\mathrm{k}}_{P r}(t)}{\tilde{\mathrm{k}}_{D e}\left(t ; D N O_{r}\right)} \cdot K C_{L_{D N}}^{D N}(t)
\end{aligned}
$$

with $K_{L_{N}}^{N}$ the overall acid-phase chemisorption coefficient of cyclic olefins belonging to the naphthenic $\operatorname{lump} L_{N}$,

$K_{L_{N}}^{, N}$ the overall acid-phase chemisorption coefficient of cyclic diolefins belonging to the naphthenic $\operatorname{lump} L_{N}$,

$K_{L_{D N}}^{D N}$ the overall acid-phase chemisorption coefficient of dicyclic olefins belonging to the dinaphthenic lump $L_{D N}$.

Consequently, the concentrations of the acyclic saturated carbenium ions are therefore given by: see Equation (A1).

with $\left\{L_{P}\right\}$ the set of paraffin lumps,

$\left\{L_{N}\right\}$ the set of naphthene lumps,

$\left\{L_{D N}\right\}$ the set of dinaphthene lumps.

\subsubsection{Isomerization Reactions}

The rate of isomerization from lump $L_{1}$ to lump $L_{2}$ is composed of the sum of the rates of all reactions involved in the isomerization of carbenium ions from lump $L_{1}$ into carbenium ions from lump $L_{2}$. For the isomerization of acyclic compounds, one therefore finds:

$$
R\left(L_{1} \Leftrightarrow L_{2}\right)=\sum_{\{z\}} n_{e, i s o}(z) \cdot \tilde{k}_{i s o}(m, n) \cdot C_{R_{m}^{+}}^{L_{1}}-\sum_{\left\{z^{\prime}\right\}} n_{e, i s o}\left(z^{\prime}\right) \cdot \tilde{k}_{i s o}(n, m) \cdot C_{R_{n}^{+}}^{L_{2}}
$$

with $R_{m}^{+}$an ion obtained by protonation of olefin $O_{i j}$ resulting from dehydrogenation of paraffin $P_{i}$ (member of lump $L_{1}$ ),

$R_{n}^{+} \quad$ an ion obtained by protonation of olefin $O_{i^{\prime} j}$, resulting from dehydrogenation of paraffin $P_{i}$, (member of lump $L_{2}$ ),

$\{z\}$ the set of elementary steps of a type of isomerization transforming the carbenium ions from lump $L_{1}$ into carbenium ions from lump $L_{2}$,

$\{z\}$ the set of elementary steps of a type of isomerization transforming the carbenium ions from lump $L_{2}$ into carbenium ions from lump $L_{1}$.

Combining the two previous equations leads to: see Equation (A2).

The forward rate coefficient for the isomerization of lump $L_{1}$ into lump $L_{2}$ is therefore given by: Equation (A3).

To explicitly isolate the 4 fundamental single event rate coefficients for isomerization, the set of isomerization steps between the ions from lump $L_{1}$ and ions from lump $L_{2}$ can be split into the 4 corresponding groups. This leads to: see Equation (A4).

with $\left\{z_{m n}\right\}$ the set of elementary steps involved in an $m-n$ isomerization of the carbenium ions of type $m$ from lump $L_{1}$ into carbenium ions of type $n$ from $L_{2}$.

In the above expression, a large number of contributions only depends on the generated reaction network, but not on the rate parameters. Hence, they can again be explicitly isolated.

Let $L C_{i s o}(m, n)$ be defined as:

$L C_{i s o}(m, n)=\sum_{\left\{z_{m n}\right\}} n_{e, i s o}(z) \cdot \frac{n_{e, P r}(m)}{n_{e, D e}\left(m, O_{i j}\right)} \cdot \frac{1}{\tilde{K}\left[o_{\eta} \Leftrightarrow O_{i j}\right]} \cdot K\left[P_{i} \Leftrightarrow O_{i j}+H_{2}\right] \cdot y_{i}$

$$
\begin{aligned}
& C_{R_{m}^{+}}=\frac{\frac{n_{e, P r}(m)}{n_{e, D e}\left(m, O_{i j}\right)} \cdot \frac{\tilde{k}_{P r}(m)}{\tilde{k}_{D e}\left(m ; O_{r}\right)} \cdot \frac{1}{\tilde{K}\left[o_{r} \Leftrightarrow O_{i j}\right]} \cdot K\left[P_{i} \Leftrightarrow O_{i j}+\mathrm{H}_{2}\right] \cdot \frac{y_{i} \cdot p_{L_{P}}}{p_{\mathrm{H}_{2}}} \cdot C_{t o t, H^{+}}}{1+\sum_{\left\{L_{P}\right\}} K_{L_{P}}^{P} \cdot \frac{p_{L_{P}}}{p_{\mathrm{H}_{2}}}+\sum_{\left\{L_{P}\right\}} K_{L_{P}}^{\prime P} \cdot \frac{p_{L_{P}}}{p_{\mathrm{H}_{2}}^{2}}+\sum_{\left\{L_{N}\right\}} K_{L_{N}}^{N} \cdot \frac{p_{L_{N}}}{p_{\mathrm{H}_{2}}}+\sum_{\left\{L_{N}\right\}} K_{L_{N}}^{\prime N} \cdot \frac{p_{L_{N}}}{p_{\mathrm{H}_{2}}^{2}}+\sum \sum_{\left\{L_{D N}\right\}} K_{L_{D N}}^{D N} \cdot \frac{p_{L_{D N}}}{p_{\mathrm{H}_{2}}}}
\end{aligned}
$$

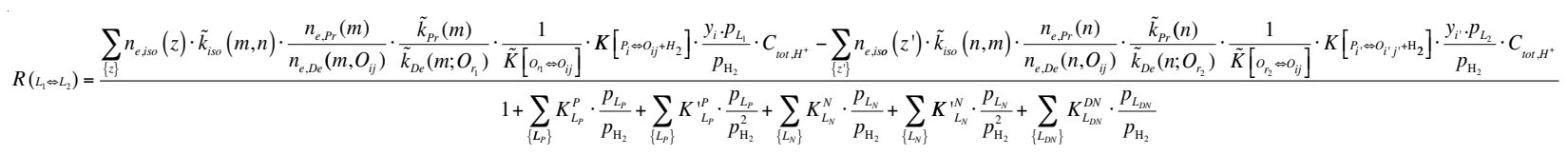

$$
\begin{aligned}
& k_{i s o}\left(L_{1} \Leftrightarrow L_{2}\right)=\sum_{\{z\}} n_{e, i s o}(z) \cdot \tilde{k}_{i s o}(m, n) \cdot \frac{n_{e, P r}(m)}{n_{e, D e}\left(m, O_{i j}\right)} \cdot \frac{\tilde{k}_{P r}(m)}{\tilde{k}_{D e}\left(m ; O_{r_{1}}\right)} \cdot \frac{1}{\tilde{K}\left[o_{r_{1}} \Leftrightarrow O_{i j}\right]} \cdot K\left[P_{i} \Leftrightarrow O_{i j}+\mathrm{H}_{2}\right] \cdot y_{i} \cdot C_{t o t, H^{+}}
\end{aligned}
$$




$$
\begin{aligned}
& k_{i s o}\left(L_{1} \leftrightarrow L_{2}\right)=\sum_{\{z, s s\}} n_{e, i s o}\left(z_{s s}\right) \cdot \tilde{k}_{i s o}(s, s) \cdot \frac{n_{e, P r}(s)}{n_{e, D e}\left(s, O_{i j}\right)} \cdot \frac{\tilde{k}_{P r}(s)}{\tilde{k}_{D e}\left(s ; O_{r_{1}}\right)} \cdot \frac{1}{\tilde{K}\left[o_{\eta} \Leftrightarrow O_{i j}\right]} \cdot K\left[P_{i} \Leftrightarrow O_{i j}+\mathrm{H}_{2}\right] \cdot y_{i} \cdot C_{t o t, H^{+}} \\
& +\sum_{\left\{z_{s t}\right\}} n_{e, i s o}\left(z_{s t}\right) \cdot \tilde{k}_{i s o}(s, t) \cdot \frac{n_{e, P r}(s)}{n_{e, D e}\left(s, O_{i j}\right)} \cdot \frac{\tilde{k}_{P r}(s)}{\tilde{k}_{D e}\left(s ; O_{r_{1}}\right)} \cdot \frac{1}{\tilde{K}\left[o_{\eta} \leftrightarrow o_{i j}\right]} \cdot K\left[P_{i} \leftrightarrow O_{i j}+\mathrm{H}_{2}\right] \cdot y_{i} \cdot C_{t o t, H^{+}} \\
& +\sum_{\left\{z_{i s}\right\}} n_{e, i s o}\left(z_{t s}\right) \cdot \tilde{k}_{i s o}(t, s) \cdot \frac{n_{e, P r}(t)}{n_{e, D e}\left(t, O_{i j}\right)} \cdot \frac{\tilde{k}_{P r}(t)}{\tilde{k}_{D e}\left(t ; O_{r_{1}}\right)} \cdot \frac{1}{\tilde{K}\left[o_{\eta} \Leftrightarrow O_{i j}\right]} \cdot K\left[P_{i} \Leftrightarrow O_{i j}+\mathrm{H}_{2}\right] \cdot y_{i} \cdot C_{t o t, H^{+}} \\
& +\sum_{\left\{z_{u}\right\}} n_{e, i s o}\left(z_{t t}\right) \cdot \tilde{k}_{i s o}(t, t) \cdot \frac{n_{e, P r}(t)}{n_{e, D e}\left(t, O_{i j}\right)} \cdot \frac{\tilde{k}_{P r}(t)}{\tilde{k}_{D e}\left(t ; O_{r_{1}}\right)} \cdot \frac{1}{\tilde{K}\left[o_{\eta} \leftrightarrow O_{i j}\right]} \cdot K\left[P_{i} \leftrightarrow O_{i j}+\mathrm{H}_{2}\right] \cdot y_{i} \cdot C_{t o t, H^{+}} \\
& k_{i s o}\left(L_{1} \Leftrightarrow L_{2}\right)=L C_{i s o}(s, s) \cdot \tilde{k}_{i s o}(s, s) \cdot \frac{\tilde{k}_{P r}(s)}{\tilde{k}_{D e}\left(s ; O_{r_{1}}\right)} \cdot C_{t o t, H^{+}}+L C_{i s o}(s, t) \cdot \tilde{k}_{i s o}(s, t) \cdot \frac{\tilde{k}_{P r}(s)}{\tilde{k}_{D e}\left(s ; O_{r_{1}}\right)} \cdot C_{t o t, H^{+}} \\
& +L C_{i s o}(t, s) \cdot \tilde{k}_{i s o}(t, s) \cdot \frac{\tilde{k}_{P r}(t)}{\tilde{k}_{D e}\left(t ; O_{r_{1}}\right)} \cdot C_{t o t, H^{+}}+L C_{i s o}(t, t) \cdot \tilde{k}_{i s o}(t, t) \cdot \frac{\tilde{k}_{P r}(t)}{\tilde{k}_{D e}\left(t ; O_{r_{1}}\right)} \cdot C_{t o t, H^{+}} \\
& R\left(L_{1} \Leftrightarrow L_{2}\right)=\frac{k_{\text {iso }}\left(L_{1} \leftrightarrow L_{2}\right) \cdot \frac{p_{L_{1}}}{p_{\mathrm{H}_{2}}}-k_{\text {iso }}\left(L_{2} \leftrightarrow L_{1}\right) \cdot \frac{p_{L_{2}}}{p_{\mathrm{H}_{2}}}}{1+\sum_{\left\{L_{P}\right\}} K_{L_{P}}^{P} \cdot \frac{p_{L_{P}}}{p_{\mathrm{H}_{2}}}+\sum_{\left\{L_{P}\right\}} K_{L_{P}}^{\prime P} \cdot \frac{p_{L_{P}}}{p_{\mathrm{H}_{2}}^{2}}+\sum_{\left\{L_{N}\right\}} K_{L_{N}}^{N} \cdot \frac{p_{L_{N}}}{p_{\mathrm{H}_{2}}}+\sum_{\left\{L_{N}\right\}} K_{L_{N}}^{\prime N} \cdot \frac{p_{L_{N}}}{p_{\mathrm{H}_{2}}^{2}}+\sum_{\left\{L_{D N}\right\}} K_{L_{D N}}^{D N} \cdot \frac{p_{L_{D N}}}{p_{\mathrm{H}_{2}}}}
\end{aligned}
$$

This coefficient is a lumping coefficient associated with the isomerization reaction between lumps $L_{1}$ and $L_{2}$ through ions of type $m$ and type $n$. It should be stressed that, for a given reaction network, this coefficient still depends on the temperature. Indeed, $y_{i}$ represents the equilibrium mole fraction of an isomer in a given lump, which evidently depends on temperature. The same holds for the dehydrogenation and olefin isomerization equilibrium constants. As mentioned above, the advantage of isolating these terms is that, for each temperature, the lumping coefficients need to be calculated only once for a given reaction network.

Hence, the forward rate coefficient for the isomerization of lump $L_{1}$ into lump $L_{2}$ is obtained from: see Equation (A5).

For the backward rate coefficient for the isomerization of lump $L_{1}$ into lump $L_{2}$, a similar expression is obtained.

Finally, the rate of isomerization of lump $L_{1}$ into lump $L_{2}$ can simply be written as: see Equation (A6).

For cyclic compounds, the rate expressions for the isomerization reactions are similar.

\subsubsection{Cyclization Reactions}

The rate of cyclization of a lump of paraffins $L_{1}$ into a lump of naphthenes $L_{2}$ is composed of the sum of the rates of all reactions linking carbenium ions from lump $L_{1}$ to carbenium ions from lump $L_{2}$. As mentioned above, this can be written as follows:

$$
\begin{aligned}
R\left(L_{1} \leftrightarrow L_{2}\right) & =\sum_{\{z\}} n_{e, c y c}(z) \cdot \tilde{k}_{c y c}(m, n) \cdot C_{O R_{n}^{+}}^{L_{1}} \\
& -\sum_{\left\{z^{\prime}\right\}} n_{e, \text { endo }}\left(z^{\prime}\right) \cdot \tilde{k}_{\text {endo }}(n, m) \cdot C_{N R_{o}^{+}}^{L_{2}}
\end{aligned}
$$

The concentrations of the acyclic unsaturated carbenium ions and of the cyclic saturated carbenium ions are given by: Equation (A7).

After combining the last three expressions, the lumping coefficients can be isolated:

$$
\begin{aligned}
L C_{c y c}(m, n)= & \sum_{\left\{z_{m m}\right\}} n_{e, c y c}(z) \cdot \frac{n_{e, P r}(m)}{n_{e, D e}\left(m, D O_{i k}\right)} \\
& \cdot \frac{1}{\tilde{K}\left[D O_{r} \leftrightarrow D o_{i k}\right]} \cdot K\left[P_{i} \Leftrightarrow D O_{i k}+2 \mathrm{H}_{2}\right] \cdot y_{i} \\
L C_{e n d o}(m, n)= & \sum_{\left\{z_{m m}^{\prime}\right\}} n_{e, e n d o}\left(z^{\prime}\right) \cdot \frac{n_{e, P r}(m)}{n_{e, D e}\left(m, N O_{i k}\right)} \\
& \cdot \frac{1}{\tilde{K}\left[N O_{r} \leftrightarrow N O_{i k}\right]} \cdot K\left[N_{i} \leftrightarrow N O_{i k}{ }^{+H_{2}}\right] \cdot y_{i}
\end{aligned}
$$




$$
\begin{aligned}
& C_{O R_{n}^{+}}=\frac{\frac{n_{e, P r}(m)}{n_{e, D e}\left(m, D O_{i k}\right)} \cdot \frac{\tilde{k}_{P r}^{\prime}(m)}{\tilde{k}_{D e}\left(m ; D O_{r}\right)} \cdot \frac{1}{\tilde{K}\left[D O_{r} \Leftrightarrow D o_{i k}\right]} \cdot K\left[P_{i} \Leftrightarrow D O_{i k}+2 \mathrm{H}_{2}\right] \cdot \frac{y_{i} \cdot p_{L_{P}}}{p_{\mathrm{H}_{2}}^{2}} \cdot C_{t o t, H^{+}}}{1+\sum_{\left\{L_{P}\right\}} K_{L_{P}}^{P} \cdot \frac{p_{L_{P}}}{p_{\mathrm{H}_{2}}}+\sum_{\left\{L_{P}\right\}} K_{L_{P}}^{\prime P} \cdot \frac{p_{L_{P}}}{p_{\mathrm{H}_{2}}^{2}}+\sum_{\left\{L_{N}\right\}} K_{L_{N}}^{N} \cdot \frac{p_{L_{N}}}{p_{\mathrm{H}_{2}}}+\sum_{\left\{L_{N}\right\}} K_{L_{N}}^{\prime N} \cdot \frac{p_{L_{N}}}{p_{\mathrm{H}_{2}}^{2}}+\sum_{\left\{L_{D N}\right\}} K_{L_{D N}}^{D N} \cdot \frac{p_{L_{D N}}}{p_{\mathrm{H}_{2}}}} \\
& C_{N R_{o}^{+}}=\frac{\frac{n_{e, P r}(n)}{n_{e, D e}\left(n, N O_{i k}\right)} \cdot \frac{\tilde{k}_{P r}(n)}{\tilde{k}_{D e}\left(n ; N O_{r}\right)} \cdot \frac{1}{\tilde{K}\left[N O_{r} \leftrightarrow N O_{i k}\right]} \cdot K\left[N_{i} \Leftrightarrow N O_{i k}+\mathrm{H}_{2}\right] \cdot \frac{y_{i} \cdot p_{L_{N}}}{p_{\mathrm{H}_{2}}} \cdot C_{t o t, H^{+}}}{1+\sum_{\left\{L_{P}\right\}} K_{L_{P}}^{P} \cdot \frac{p_{L_{P}}}{p_{\mathrm{H}_{2}}}+\sum_{\left\{L_{P}\right\}} K_{L_{P}}^{\prime P} \cdot \frac{p_{L_{P}}}{p_{\mathrm{H}_{2}}^{2}}+\sum_{\left\{L_{N}\right\}} K_{L_{N}}^{N} \cdot \frac{p_{L_{N}}}{p_{\mathrm{H}_{2}}}+\sum_{\left\{L_{N}\right\}} K_{L_{N}}^{\prime N} \cdot \frac{p_{L_{N}}}{p_{\mathrm{H}_{2}}^{2}}+\sum_{\left\{L_{D N}\right\}} K_{L_{D N}}^{D N} \cdot \frac{p_{L_{D N}}}{p_{\mathrm{H}_{2}}}} \\
& R\left(L_{1} \Leftrightarrow L_{2}\right)=\frac{k_{c y c}\left(L_{1} \Leftrightarrow L_{2}\right) \cdot \frac{p_{L_{1}}}{p_{\mathrm{H}_{2}}^{2}}-k_{\text {endo }}\left(L_{2} \Leftrightarrow L_{1}\right) \cdot \frac{p_{L_{2}}}{p_{\mathrm{H}_{2}}}}{1+\sum_{\left\{L_{P}\right\}} K_{L_{P}}^{P} \cdot \frac{p_{L_{P}}}{p_{\mathrm{H}_{2}}}+\sum_{\left\{L_{P}\right\}} K_{L_{P}}^{\prime P} \cdot \frac{p_{L_{P}}}{p_{\mathrm{H}_{2}}^{2}}+\sum_{\left\{L_{N}\right\}} K_{L_{N}}^{N} \cdot \frac{p_{L_{N}}}{p_{\mathrm{H}_{2}}}+\sum_{\left\{L_{N}\right\}} K_{L_{N}}^{\prime N} \cdot \frac{p_{L_{N}}}{p_{\mathrm{H}_{2}}^{2}}+\sum_{\left\{L_{D N}\right\}} K_{L_{D N}}^{D N} \cdot \frac{p_{L_{D N}}}{p_{\mathrm{H}_{2}}}}
\end{aligned}
$$

The forward rate coefficient and the backward rate coefficient for the cyclization of lump $L_{1}$ into lump $L_{2}$ are then given by:

$$
\begin{aligned}
k_{c y c}\left(L_{1} \leftrightarrow L_{2}\right)= & L C_{c y c}(s, s) \cdot \tilde{k}_{c y c}(s, s) \cdot \frac{\tilde{k}_{P r}^{\prime}(s)}{\tilde{k}_{D e}\left(s ; D O_{r}\right)} \cdot C_{t o t, H^{+}} \\
& +L C_{c y c}(s, t) \cdot \tilde{k}_{c y c}(s, t) \cdot \frac{\tilde{k}_{P_{r}}^{\prime}(s)}{\tilde{k}_{D e}\left(s ; D O_{r}\right)} \cdot C_{t o t, H^{+}} \\
& +L C_{c y c}(t, s) \cdot \tilde{k}_{c y c}(t, s) \cdot \frac{\tilde{k}_{P r}^{\prime}(t)}{\tilde{k}_{D e}\left(t ; D O_{r}\right)} \cdot C_{t o t, H^{+}} \\
& +L C_{c y c}(t, t) \cdot \tilde{k}_{c y c}(t, t) \cdot \frac{\tilde{k}_{P r}^{\prime}(t)}{\tilde{k}_{D e}\left(t ; D O_{r}\right)} \cdot C_{t o t, H^{+}} \\
k_{\text {endo }}\left(L_{2} \leftrightarrow L_{1}\right)= & L C_{\text {endo }}(s, s) \cdot \tilde{k}_{\text {endo }}(s, s) \cdot \frac{\tilde{k}_{P r}(s)}{\tilde{k}_{D e}\left(s ; N O_{r}\right)} \cdot C_{t o t, H^{+}} \\
& +L C_{\text {endo }}(s, t) \cdot \tilde{k}_{\text {endo }}(s, t) \cdot \frac{\tilde{k}_{P r}(s)}{\tilde{k}_{D e}\left(s ; N O_{r}\right)} \cdot C_{t o t, H^{+}} \\
& +L C_{\text {endo }}(t, s) \cdot \tilde{k}_{\text {endo }}(t, s) \cdot \frac{\tilde{k}_{P r}(t)}{\tilde{k}_{D e}\left(t ; N O_{r}\right)} \cdot C_{t o t, H^{+}} \\
& +L C_{\text {endo }}(t, t) \cdot \tilde{k}_{\text {endo }}(t, t) \cdot \frac{\tilde{k}_{P r}(t)}{\tilde{k}_{D e}\left(t ; N O_{r}\right)} \cdot C_{t o t, H^{+}}
\end{aligned}
$$

Finally, the rate of cyclization of lump $L_{1}$ into lump $L_{2}$ can be written as: see Equation (A8).

\subsubsection{Cracking Reactions}

In the case of (acyclic or exocyclic) cracking reactions of a lump $L_{1}$ to lumps $L_{2}$ and $L_{3}$, the rate of cracking is given by the sum of the rates of all cracking reactions linking carbenium ions from lump $L_{1}$ to carbenium ions and olefins from lumps $L_{2}$ and $L_{3}$. For the cracking of acyclic saturated carbenium ions, this can be written as follows:

$$
R\left(L_{1} \rightarrow L_{2}+L_{3}\right)=\sum_{\{z\}} n_{e, a c y c}(z) \cdot \tilde{k}_{a c y c}\left(m ; n, O^{L_{3}}\right) \cdot C_{R_{m}^{+}}^{L_{1}}
$$

The expression for the concentration of the acyclic saturated carbenium ions has been derived previously. Combining both expressions results in: see Equation (A9).

For the rate coefficients for cracking, there is a thermodynamic constraint relating the rate coefficients for cracking to the rate coefficients for their reverse reaction, i.e. alkylation (Vynckier and Froment, 1991):

$$
k_{a c y c}\left(m ; n, O\left(C_{k}\right)\right)=k_{a l k}(n, m) \cdot \frac{k_{P r}(n)}{k_{D e}\left(n ; O\left(C_{i-k}\right)\right)} \cdot \frac{k_{D e}\left(m ; O\left(C_{i}\right)\right)}{k_{P r}(m)}
$$

Combining this thermodynamic constraint with those for the deprotonation steps, one finds:

$$
\tilde{k}_{a c y c}(m ; n, O)=\tilde{k}_{a l k}(n, m) \cdot \frac{\tilde{k}_{P r}(n)}{\tilde{k}_{D e}\left(n ; O_{r_{2}}\right)} \cdot \frac{\tilde{k}_{D e}\left(m ; O_{r_{1}}\right)}{\tilde{k}_{P r}(m)} \cdot \tilde{K}\left[o_{\eta} \Leftrightarrow O_{r_{2}}+0\right]
$$




$$
\begin{aligned}
& R\left(L_{1} \rightarrow L_{2}+L_{3}\right)=\frac{\sum_{\{z\}} n_{e, a c y c}(z) \cdot \tilde{k}_{a c y c}(m ; n, O) \cdot \frac{n_{e, P r}(m)}{n_{e, D e}\left(m, O_{i j}\right)} \cdot \frac{\tilde{k}_{P r}(m)}{\tilde{k}_{D e}\left(m ; O_{r_{1}}\right)} \cdot \frac{1}{\tilde{K}\left[o_{\eta} \Leftrightarrow O_{i j}\right]} \cdot K\left[p_{i} \Leftrightarrow o_{i j}+\mathrm{H}_{2}\right] \cdot \frac{y_{i} \cdot p_{L_{1}}}{p_{\mathrm{H}_{2}}} \cdot C_{t o t, H^{+}}}{1+\sum_{\left\{L_{P}\right\}} K_{L_{P}}^{P} \cdot \frac{p_{L_{P}}}{p_{\mathrm{H}_{2}}}+\sum_{\left\{L_{P}\right\}} K_{L_{P}}^{\prime P} \cdot \frac{p_{L_{P}}}{p_{\mathrm{H}_{2}}^{2}}+\sum_{\left\{L_{N}\right\}} K_{L_{N}}^{N} \cdot \frac{p_{L_{N}}}{p_{\mathrm{H}_{2}}}+\sum_{\left\{L_{N}\right\}} K_{L_{N}}^{\prime N} \cdot \frac{p_{L_{N}}}{p_{\mathrm{H}_{2}}^{2}}+\sum_{\left\{L_{D N}\right\}} K_{L_{D_{N}}}^{D N} \cdot \frac{p_{L_{D N}}}{p_{\mathrm{H}_{2}}}} \\
& R\left(L_{1} \rightarrow L_{2}+L_{3}\right)=\frac{\sum_{\{z\}} n_{e, a c y c}(z) \cdot \tilde{k}_{a l k}(n, m) \cdot \frac{n_{e, P r}(m)}{n_{e, D e}\left(m, O_{i j}\right)} \cdot \frac{\tilde{k}_{P r}(n)}{\tilde{k}_{D e}\left(n ; O_{r_{2}}\right)} \cdot \frac{\tilde{K}\left[o_{\eta} \Leftrightarrow O_{r^{2}}+0\right]}{\tilde{K}\left[o_{\eta} \Leftrightarrow O_{i j}\right]} \cdot K\left[P_{i} \Leftrightarrow O_{i j}+\mathrm{H}_{2}\right] \cdot \frac{y_{i} \cdot p_{L_{1}}}{p_{\mathrm{H}_{2}}} \cdot C_{t o t, H^{+}}}{1+\sum_{\left\{L_{P}\right\}} K_{L_{P}}^{P} \cdot \frac{p_{L_{P}}}{p_{\mathrm{H}_{2}}}+\sum_{\left\{L_{P}\right\}} K_{L_{P}}^{\prime P} \cdot \frac{p_{L_{P}}}{p_{\mathrm{H}_{2}}^{2}}+\sum_{\left\{L_{N}\right\}} K_{L_{N}}^{N} \cdot \frac{p_{L_{N}}}{p_{\mathrm{H}_{2}}}+\sum_{\left\{L_{N}\right\}} K_{L_{N}}^{\prime N} \cdot \frac{p_{L_{N}}}{p_{\mathrm{H}_{2}}^{2}}+\sum_{\left\{L_{D N}\right\}} K_{L_{D N}}^{D N} \cdot \frac{p_{L_{D N}}}{p_{\mathrm{H}_{2}}}} \\
& k_{a c y c}\left(L_{1} \rightarrow L_{2}+L_{3}\right)=\sum_{\{z\}} n_{e, a c y c}(z) \cdot \tilde{k}_{a l k}(n, m) \cdot \frac{n_{e, P r}(m)}{n_{e, D e}\left(m, O_{i j}\right)} \cdot \frac{\tilde{k}_{P r}(n)}{\tilde{k}_{D e}\left(n ; O_{r_{2}}\right)} \cdot \frac{\tilde{K}\left[o_{n_{1}} \Leftrightarrow o_{r_{2}+O}\right]}{\tilde{K}\left[o_{\eta} \Leftrightarrow O_{i j}\right]} \cdot K\left[P_{i} \Leftrightarrow o_{i j}+H_{2}\right] \cdot y_{i} \cdot C_{t o t, H^{+}} \\
& L C_{a c y c}(m, n)=\sum_{\left\{z_{m m}\right\}} n_{e, a c y c}\left(z_{m n}\right) \cdot \frac{n_{e, P r}(m)}{n_{e, D e}\left(m, O_{i j}\right)} \cdot \frac{\tilde{K}\left[o_{n} \Leftrightarrow o_{r_{2}}+0\right]}{\tilde{K}\left[o_{r_{1}} \Leftrightarrow o_{i j}\right]} \cdot K\left[P_{i} \Leftrightarrow o_{i j}+\mathrm{H}_{2}\right] \cdot y_{i} \\
& R\left(L_{1} \rightarrow L_{2}+L_{3}\right)=\frac{k_{\text {acyc }}\left(L_{1} \rightarrow L_{2}+L_{3}\right) \cdot \frac{p_{L_{1}}}{p_{\mathrm{H}_{2}}}}{1+\sum_{\left\{L_{P}\right\}} K_{L_{P}}^{P} \cdot \frac{p_{L_{P}}}{p_{\mathrm{H}_{2}}}+\sum_{\left\{L_{P}\right\}} K_{L_{P}}^{\prime P} \cdot \frac{p_{L_{P}}}{p_{\mathrm{H}_{2}}^{2}}+\sum_{\left\{L_{N}\right\}} K_{L_{N}}^{N} \cdot \frac{p_{L_{N}}}{p_{\mathrm{H}_{2}}}+\sum_{\left\{L_{N}\right\}} K_{L_{N}}^{\prime N} \cdot \frac{p_{L_{N}}}{p_{\mathrm{H}_{2}}^{2}}+\sum_{\left\{L_{D N}\right\}} K_{L_{D N}}^{D N} \cdot \frac{p_{L_{D N}}}{p_{\mathrm{H}_{2}}}}
\end{aligned}
$$

This means that all rate coefficients for cracking can be calculated from the alkylation rate coefficients by means of the above equation. This will therefore greatly reduce the number of rate coefficients in the catalytic reforming model. This expression for the rate coefficients for cracking can now be introduced in the rate equation for cracking to yield: see Equation (A10).

Hence, the rate coefficient for cracking is given by: see Equation (A11).

The lumping coefficients for the 4 types of acyclic $\beta$-scission can now be defined as follows: see Equation (A12).

These lumping coefficients allows rewriting the rate coefficient for cracking as:

$$
\begin{aligned}
k_{a c y c}\left(L_{1} \rightarrow L_{2}+L_{3}\right)= & L C_{a c y c}(s, s) \cdot \tilde{k}_{a l k}(s, s) \cdot \frac{\tilde{k}_{P r}(s)}{\tilde{k}_{D e}\left(s ; O_{r_{2}}\right)} \cdot C_{t o t, H^{+}} \\
& +L C_{a c y c}(s, t) \cdot \tilde{k}_{a l k}(t, s) \cdot \frac{\tilde{k}_{P r}(t)}{\tilde{k}_{D e}\left(t ; O_{r_{2}}\right)} \cdot C_{t o t, H^{+}} \\
& +L C_{a c y c}(t, s) \cdot \tilde{k}_{a l k}(s, t) \cdot \frac{\tilde{k}_{P r}(s)}{\tilde{k}_{D e}\left(s ; O_{r_{2}}\right)} \cdot C_{t o t, H^{+}} \\
& +L C_{a c y c}(t, t) \cdot \tilde{k}_{a l k}(t, t) \cdot \frac{\tilde{k}_{P r}(t)}{\tilde{k}_{D e}\left(t ; O_{r_{2}}\right)} \cdot C_{t o t, H^{+}}
\end{aligned}
$$

Finally, the rate of cracking of lump $L_{1}$ into lumps $L_{2}$ and $L_{3}$ can be written as: see Equation (A13).

The procedure to derive the lumping coefficients is exactly similar for the exocyclic cracking reactions. One then finds:

$$
\begin{aligned}
& L C_{e x o N}(m, n)=\sum_{\left\{z_{m n}\right\}} n_{e, e x o N}\left(z_{m n}\right) \\
& \cdot \frac{n_{e, P r}(m)}{n_{e, D e}\left(m, N O_{i k}\right)} \cdot \frac{\tilde{K}\left[N O_{\eta} \leftrightarrow O_{n^{2}}+\mathrm{NO}\right]}{\tilde{K}\left[N O_{r 1} \oplus N O_{i k}\right]} \cdot K\left[N_{i} \leftrightarrow N O_{i k}+\mathrm{H}_{2}\right] \cdot y_{i} \\
& L C_{\text {exoO }}(m, n)=\sum_{\left\{z_{m n}\right\}} n_{e, e x o O}\left(z_{m n}\right) \\
& \cdot \frac{n_{e, P r}(m)}{n_{e, D e}\left(m, N O_{i k}\right)} \cdot \frac{\tilde{K}\left[N O_{\eta} \leftrightarrow N O_{n^{2}}+\mathrm{O}\right]}{\tilde{K}\left[N O_{r 1} \oplus N O_{i k}\right]} \cdot K\left[N_{i} \leftrightarrow N O_{i k}+\mathrm{H}_{2}\right] \cdot y_{i}
\end{aligned}
$$

\subsection{Calculation of the Rates of Metal-catalyzed Reactions between Lumps}

\subsubsection{Demethylation Reactions}

Deriving the rate of demethylation of a lump $L_{1}$ to lump $L_{2}$ and methane $\left(P_{1}\right)$ will be similar to the case of the cracking 
reactions above. According to the reaction mechanism and the kinetic equations for the metal phase proposed above, in the case of paraffins the reaction rate between lumps is expressed as follows:

$$
R\left(L_{1} \rightarrow L_{2}+P_{1}\right)=\sum_{\{z\}} n_{s, D M}(z) \cdot \bar{k}_{D M}(m) \cdot K_{P} \cdot p_{P_{i}} \cdot p_{\mathrm{H}_{2}}^{1-a} \cdot C_{M}^{2}
$$

with $\{z\}$

the set of demethylation steps transforming the species from lump $L_{1}$ into species from lump $L_{2}$ with the formation of methane,

$n_{s, D M}(z)$ the number of identifiable pathways to remove a methyl group from a species belonging to lump $L_{1}$ while arriving at the same species belonging to lump $L_{2}$,

$\bar{k}_{D M}(m)$ the rate coefficient of demethylation for a methyl group linked to an atom of type $m$,

$K_{P} \quad$ the adsorption coefficient for paraffins on the metal phase,

$p_{p_{i}} \quad$ the partial pressure of paraffin $P_{i}$,

$p_{\mathrm{H}_{2}} \quad$ the partial pressure of hydrogen,

$a$ degree of unsaturation of the adsorbed intermediate,

$C_{M} \quad$ the concentration of free metal sites.

Neglecting the adsorption of intermediate unsaturated compounds on the metal phase, the balance equation on the metal sites becomes:

$$
\begin{aligned}
C_{t o t, M}= & C_{M} \cdot 1+\sum_{i}\left(K_{P} \cdot p_{P_{i}}\right)+\sum_{j}\left(K_{N} \cdot p_{N_{j}}\right)+\sum_{k}\left(K_{D N} \cdot p_{D N_{k}}\right) \\
& +\sum_{l}\left(K_{A} \cdot p_{A_{l}}+K_{N A} \cdot p_{N A_{l}}+K_{D A} \cdot p_{D A_{l}}\right)=C_{M} \cdot D E N_{M}
\end{aligned}
$$

The denominator can now be rewritten as:

$$
\begin{aligned}
D E N_{M} & =1+K_{P} \sum_{\left\{L_{p}\right\}} p_{L_{P}}+K_{N} \sum_{\left\{L_{N}\right\}} p_{L_{N}} \sum_{\{N\}} y_{n}+K_{A} \sum_{\left\{L_{N}\right\}} p_{L_{N}} \sum_{\{A\}} y_{a} \\
& +K_{D N} \sum_{\left\{L_{D N}\right\}} p_{L_{D N}} \sum_{\{D N\}} y_{d n}+K_{N A} \sum_{\left\{L_{D N}\right\}} p_{L_{D N}} \sum_{\{N A\}} y_{n a}+K_{D A} \sum_{\left\{L_{D N}\right\}} p_{L_{D N}} \sum_{\{D A\}} y_{d a}
\end{aligned}
$$

with $\{N\}$ the set of naphthenes from lump $L_{N}$,

$\{A\}$ the set of aromatics from lump $L_{N}$,

$\{D N\}$ the set of dinaphthenes from lump $L_{D N}$,

$\{N A\}$ the set of naphthenoaromatics from lump $L_{D N}$,

$\{D A\}$ the set of diaromatics from lump $L_{D N}$.

This denominator can be reorganized to isolate the partial pressures of the various lumps:

$$
\begin{aligned}
D E N_{M}= & 1+K_{P} \sum_{\left\{L_{P}\right\}} p_{L_{P}}+\left(K M_{L_{N}}^{N} \cdot K_{N}+K M_{L_{N}}^{A} \cdot K_{A}\right) \cdot \sum_{\left\{L_{N}\right\}} p_{L_{N}} \\
& +\left(K M_{L_{D N}}^{D N} \cdot K_{D N}+K M_{L_{D N}}^{N A} \cdot K_{N A}+K M_{L_{D N}}^{D A} \cdot K_{D A}\right) \cdot \sum_{\left\{L_{D N}\right\}} p_{L_{D N}}
\end{aligned}
$$

with:

$$
\begin{aligned}
K M_{L_{N}}^{N} & =\sum_{\{N\}} y_{n}, K M_{L_{N}}^{A}=\sum_{\{A\}} y_{a} \\
K M_{L_{D N}}^{D N} & =\sum_{\{D N\}} y_{d n}, K M_{L_{D N}^{N A}}^{N A}=\sum_{\{N A\}} y_{n a}, K M_{L_{D N}}^{D A}=\sum_{\{D A\}} y_{d a}
\end{aligned}
$$

Introducing the expression for the concentration of free metal sites leads to the following expression for the rate of demethylation of a lump $L_{1}$ to lump $L_{2}$ and methane:

$$
R\left(L_{1} \rightarrow L_{2}+P_{1}\right)=\sum_{\{z\}} n_{s, D M}(z) \cdot \bar{k}_{D M}(m) \cdot K_{P} \cdot y_{i} \cdot p_{L_{P_{1}}} \cdot p_{\mathrm{H}_{2}}^{1-a} \cdot \frac{C_{\text {tot, } M}^{2}}{D E N_{M}^{2}}
$$

Using the same approach as for the acid-catalyzed steps, the lumping coefficient can be defined as follows:

$$
L C_{D M}(m)=\sum_{\{z\}} n_{s, D M}(z) \cdot y_{i}
$$

The rate coefficient for demethylation can now be written as:

$$
\begin{aligned}
& k_{D M}\left(L_{1} \rightarrow L_{2}+P_{1}\right)= \\
& {\left[\bar{k}_{D M}(s) \cdot L C_{D M}(s)+\bar{k}_{D M}(t) \cdot L C_{D M}(t)+\bar{k}_{D M}(q) \cdot L C_{D M}(q)\right] \cdot K_{P} \cdot C_{t o t, M}^{2}}
\end{aligned}
$$

Hence, the final expression for the rate of demethylation of a lump $L_{1}$ to lump $L_{2}$ and methane is given as:

$$
R\left(L_{1} \rightarrow L_{2}+P_{1}\right)=\frac{k_{D M}\left(L_{1} \rightarrow L_{2}+P_{1}\right) \cdot p_{\mathrm{H}_{2}}^{1-a} \cdot p_{L_{P_{1}}}}{D E N_{M}^{2}}
$$

The expressions for the demethylation reactions are similar in the case of naphthenes and dinaphthenes. The demethylation of toluene and deethylation of ethylbenzene are prohibited reactions in the network. Hence, this is reflected by summing on demethylation steps when calculating the lumping coefficient.

\subsubsection{Deethylation Reactions}

The calculations are exactly similar to those in the case of demethylation reactions. Hence, in the case of paraffins, the following relations are obtained:

$$
L C_{D E}(m)=\sum_{\{z\}} n_{s, D E}(z) \cdot y_{i}
$$

$$
\begin{aligned}
& k_{D E}\left(L_{1} \rightarrow L_{2}+P_{2}\right)= \\
& {\left[\bar{k}_{D E}(s) \cdot L C_{D E}(s)+\bar{k}_{D E}(t) \cdot L C_{D E}(t)+\bar{k}_{D E}(q) \cdot L C_{D E}(q)\right] \cdot K_{P} \cdot C_{\text {tot }, M}^{2}} \\
& R\left(L_{1} \rightarrow L_{2}+P_{2}\right)=\frac{k_{D E}\left(L_{1} \leftrightarrow L_{2}+P_{1}\right) \cdot p_{\mathrm{H}_{2}}^{1-a} \cdot p_{L_{\mathrm{P}}}}{D E N_{M}^{2}}
\end{aligned}
$$

\section{APPLICATION TO CATALYTIC REFORMING OF $\mathrm{A} \mathrm{C}_{7}$ CUT}

The catalytic reforming model described previously has been compared with experimental data in order to validate the methodology. 


\subsection{Experimentation}

\subsubsection{Pilot Unit}

The experimental data were obtained on a pilot unit at IFPEN, which includes 4 main sections (Fig. 4):

- a feedstock pretreatment section;

- a reaction section;

- a recycle section;

- an effluent separation section.

The pretreatment section controls the degree of humidity of the feedstock, reducing it if necessary. Too much water would lead to dechlorination of the catalyst. The feedstock must therefore contain less than 10 ppm water.

The reaction section consists of a tubular reactor, operating in downflow with a fixed catalyst bed. The spherical catalyst beads are diluted in five reaction areas by inert alumina. The samples are taken by capillaries in the inert areas that separate the reaction areas. These capillaries are connected to an on-line gas chromatograph.

The recycling section is used to regulate the partial pressures of hydrogen and hydrocarbons in order to keep the $\mathrm{H}_{2} / \mathrm{HC}$ ratio constant. Hydrogen can be added to reduce the catalyst during start-up and to compensate for hydrogen consumption with some feeds under certain operations conditions.

The effluent separation section is used to separate the hydrogen-rich gas (one fraction being recycled and the rest purged) and the condensed liquid hydrocarbons. The liquid fraction is then depressurized and sent to a stabilization column to recover the light hydrocarbons (methane to butane) and the reformate $\left(\mathrm{C}_{5+}\right)$ separately.

\subsubsection{Effluent Analysis}

The samples taken in the reactor are sent to an on-line HP5890 gas chromatograph. A PONA column connected to a Flame Ionization Detector (FID) analyses the hydrocarbons (paraffins, olefins, naphthenes and aromatics) and a MolSieve column connected to a Thermal Conductivity Detector (TCD) is used to separate and quantify the permanent gases (hydrogen, methane, nitrogen, oxygen). The data is acquired by Chemstation software and the chromatogram is analyzed by Carburane software, developed at IFPEN.

\subsubsection{Operating Conditions}

\section{Catalyst}

An industrial $\mathrm{PtSn} / \gamma-\mathrm{Al}_{2} \mathrm{O}_{3}$ catalytic reforming catalyst was used for these studies. The catalyst consisted of 2-mm diameter beads.

\section{Feedstock}

The feedstock used is a model feedstock that is mainly composed of heptane isomers and some dibranched cyclopentanes (Tab. 4). The feed contains over $98 \%$ of $\mathrm{C}_{7}$ components, about $1.3 \mathrm{wt} \%$ of $\mathrm{C}_{6}$ components, and less than $0.6 \mathrm{wt} \%$ of $\mathrm{C}_{8+}$ components.

\section{Experimental Program}

The operating conditions corresponding to the experimental data are detailed in Table 5. Experimental data were acquired in a series of 21 tests. For each test, the analyses were performed at 4 points in the reactor (sampling by capillaries), so as to obtain 4 residence times.

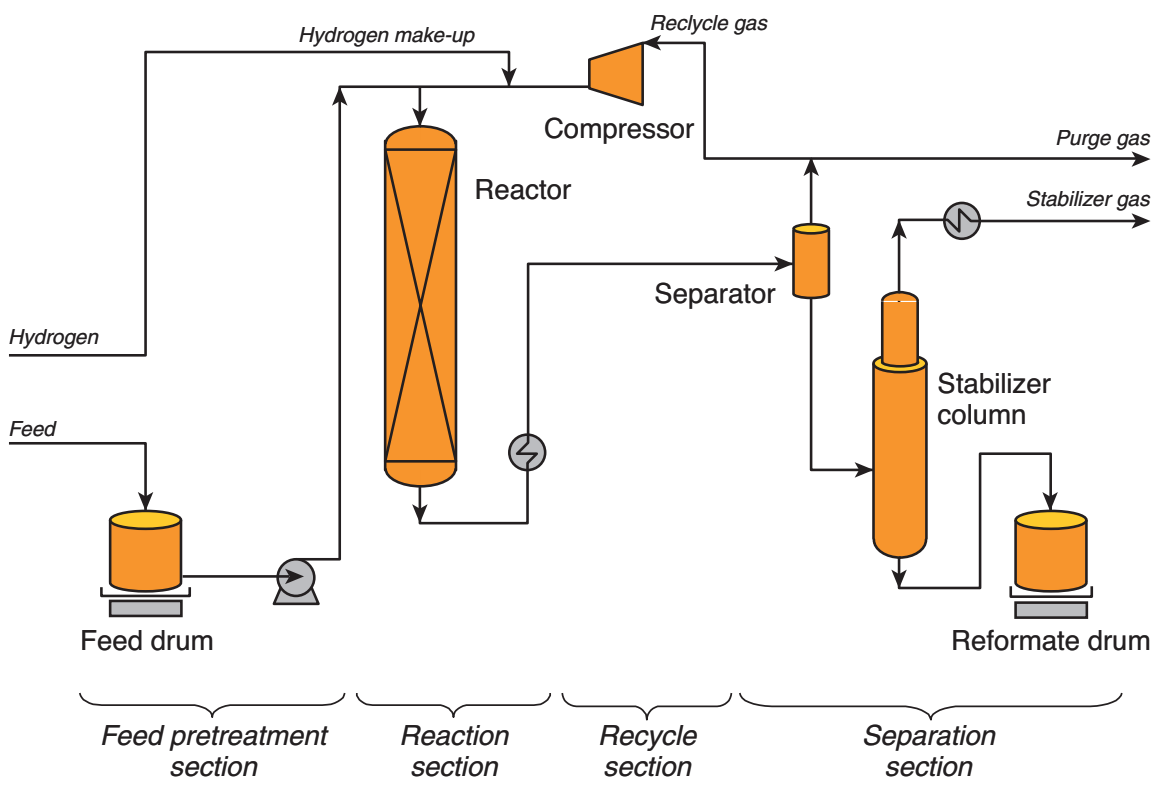

Figure 4

Schematic diagram of the catalytic reforming pilot unit. 
TABLE 4

Composition of the heptane isomer feedstock

\begin{tabular}{|c|c|}
\hline Compounds & Content (wt $\%$ ) \\
\hline nP-6 & 0.18 \\
\hline moN6 & 0.12 \\
\hline N6 & 1.03 \\
\hline $\mathrm{nP7}$ & 13.15 \\
\hline moP7 & 61.76 \\
\hline $\operatorname{diP} 7$ & 17.17 \\
\hline triP7 & 0.55 \\
\hline moN7 & 0.20 \\
\hline diN7 & 5.26 \\
\hline moA7 & 0.02 \\
\hline $\mathrm{nP8}$ & 0.01 \\
\hline moP8 & 0.06 \\
\hline diP8 & 0.38 \\
\hline triP8 & 0.01 \\
\hline moN8 & 0.01 \\
\hline $\operatorname{diN} 8$ & 0.06 \\
\hline $\operatorname{moA} 8$ & 0.01 \\
\hline N9 & 0.02 \\
\hline
\end{tabular}

TABLE 5

Operating conditions of the kinetic experiments

\begin{tabular}{c|c|c|c|c|c}
\hline Experiment & $\begin{array}{c}P_{\text {tot }} \\
(\text { bar })\end{array}$ & $\begin{array}{c}P_{\mathrm{H}_{2}} \\
(\mathrm{bar})\end{array}$ & $\begin{array}{c}P_{\mathrm{HC}} \\
(\mathrm{bar})\end{array}$ & $\begin{array}{c}\mathrm{H}_{2} / \mathrm{HC} \\
(\mathrm{mol} / \mathrm{mol})\end{array}$ & $\begin{array}{c}\text { Temperature } \\
\left({ }^{\circ} \mathrm{C}\right)\end{array}$ \\
\hline 1 & 11.5 & 9.8 & 1.7 & 5.6 & 460 \\
\hline 2 & 11.0 & 9.8 & 1.2 & 8.0 & 460 \\
\hline 3 & 10.5 & 9.7 & 0.8 & 12.0 & $450,460,485$ \\
\hline 4 & 10.0 & 8.9 & 1.1 & 8.0 & 460 \\
\hline 5 & 7.0 & 6.2 & 0.8 & 8.0 & 460 \\
\hline 6 & 6.0 & 5.2 & 0.8 & 6.5 & 460 \\
\hline
\end{tabular}

\subsection{Identification of Parameters}

The model was compared to the experimental data obtained on the pilot unit. The detailed analyses of the reaction mixture were relumped in terms of the 22 lumps. Parameter identification was performed by means of a classical Levenberg-Marquardt algorithm (Levenberg, 1944; Marquardt, 1963), which minimized the weighted sum of the squares of the differences between the experimental and simulated mole fractions of the various effluents.

A total of 41 parameters was identified by regressing against 1680 responses, leaving 1639 degrees of freedom. During the parameter estimation, the natural logarithms of the kinetic parameters at $460^{\circ} \mathrm{C}$ were estimated, together with their activation energy or adsorption enthalpy. The adsorption enthalpies for the adsorption coefficients on the metal phase could not be estimated at the $95 \%$ significance level, and were therefore set to zero. To avoid divergence of the optimizer, limits were imposed on the activation energies, which were only allowed to vary between $40 \mathrm{~kJ} / \mathrm{mol}$ and $400 \mathrm{~kJ} / \mathrm{mol}$. After parameter identification, none of the activation energies was stuck at these boundaries. At the optimum, a statistical analysis was performed on the parameters, and all model parameters were found to be significant at the $95 \%$ confidence level $(t$-value $>2)$. The values of the estimated parameters, the confidence intervals, and their $\mathrm{t}$-values are given in Table 6. Finally, the significance of the global regression was assessed by means of the ratio of the mean regression sum of squares to the mean residual sum of squares, which is distributed according to an $F$ distribution (Himmelblau, 1970; Kittrell, 1970; Froment and Hosten, 1981; Bockhorn, 1990). A high value of the calculated $F$ ratio corresponds to a high significance of the global regression. In our case, an $F$-value for the global regression of 127000 was obtained, clearly illustrating the significance of the regression at the $95 \%$ probability level.

Inspection of the correlation matrix between parameters showed that the parameters were almost fully decorrelated. Strong correlations $(|r|>0.875)$ were found between only three parameter pairs out of the 820 combinations: the preexponential factors $\boldsymbol{A}^{*}$ of $\widetilde{k}_{c y c}(s ; s)$ and $\widetilde{K}_{P r / D e}(s ; D O)$ were negatively correlated, as well as the pre-exponential factors $A^{*}$ of $\widetilde{k}_{i s o}(t ; t)$ and $\widetilde{K}_{P r / D e}(t ; O)$, and the pre-exponential factors $A^{*}$ of $\widetilde{k}_{\text {alk }}(s ; s)$ and $\widetilde{K}_{P r / D e}(s ; O)$. A somewhat weaker positive correlation $(0.875>|r|>0.825)$ was found between the pre-exponential factors $A^{*}$ of $\bar{k}_{D M}(q)$ and $\bar{k}_{D E}(q)$. Three more parameter pairs had an even weaker correlation $(0.825>|r|>0.800)$ : the pre-exponential factors $\boldsymbol{A}^{*}$ of $\widetilde{k}_{a l k}(s ; t)$ and $\widetilde{k}_{a l k}(t ; t)$, the pre-exponential factor $A^{*}$ of $\bar{k}_{D M}(q)$ and the adsorption coefficient $K_{p}$, and the pre-exponential factor $A^{*}$ of $k_{D E}(q)$ and the adsorption coefficient $K_{p}$. The other 813 parameter pairs had correlation coefficients that were between -0.8 and 0.8 .

Looking at the parameter values themselves, the isomerization rate coefficient $\widetilde{k}_{i s o}(t ; t)$ is larger than $\widetilde{k}_{i s o}(s ; s)$, which is in turn larger than $\widetilde{k}_{i s o}(s ; t)$. For the alkylation rate coefficients, $\widetilde{k}_{a l k}(s ; t)>\widetilde{k}_{\text {alk }}(t ; s)>\widetilde{k}_{\text {alk }}(s ; s)$. Moreover, the activation energies for these three steps were found to be almost identical. Finally, it can also be concluded that the rate of PCP-branching isomerization is larger than that of $\beta$-scission, which is consistent with the experimental observations. For the cyclization reactions, the kinetic parameters at $460^{\circ} \mathrm{C}$ are in the following order: $\widetilde{k}_{c y c}(s ; t)>\widetilde{k}_{c y c}(s ; s)>\widetilde{k}_{c y c}(t ; s)$. For the hydrogenolysis reactions, the hydrogenolysis of a bond to a quaternary carbon atom is the fastest in each series, while the scission at a secondary carbon atom is the slowest. The rate coefficients for deethylation are somewhat lower than those for demethylation, except for the hydrogenolysis at a quaternary carbon atom. Concerning the activation energies for 


\section{TABLE 6}

Kinetic parameters of the single event model for catalytic reforming (parameter value, lower limit of the 95\% confidence interval (LL), upper limit of the $95 \%$ confidence interval (UL), $t$-value)

\begin{tabular}{|c|c|c|c|c|c|c|c|c|}
\hline \multirow{2}{*}{$\begin{array}{l}\text { Equilibrium constants } \\
\text { by carbocation }\end{array}$} & \multicolumn{3}{|c|}{$A^{*}$} & \multirow{2}{*}{$t$-Value $\ln \left(A^{*}\right)$} & \multicolumn{3}{|c|}{$\Delta H(\mathrm{~kJ} / \mathrm{mol})$} & \multirow{2}{*}{$t$-Value $\Delta t$} \\
\hline & Value & LL & UL & & Value & LL & UL & \\
\hline$\widetilde{K}_{P r / D e}(s ; O)$ & $7.53 \mathrm{E}+00$ & $3.66 \mathrm{E}+00$ & $1.55 \mathrm{E}+01$ & 5.6 & -95.6 & -164.4 & -26.8 & -2.8 \\
\hline$\widetilde{K}_{P r / D e}(t ; O)$ & $1.26 \mathrm{E}+01$ & $3.72 \mathrm{E}+00$ & $4.26 \mathrm{E}+01$ & 4.2 & -101.7 & -196.5 & -6.9 & -2.1 \\
\hline$\widetilde{K}_{P r / D e}(s ; N O)$ & $1.27 \mathrm{E}+00$ & $1.07 \mathrm{E}+00$ & $1.51 \mathrm{E}+00$ & 2.7 & -91.8 & -158.8 & -24.9 & -2.7 \\
\hline$\widetilde{K}_{P r / D e}(s ; D O)$ & $4.10 \mathrm{E}-03$ & 3.37E-04 & 4.98E-02 & -4.4 & -52.4 & -86.7 & -18.1 & -3.1 \\
\hline \multirow{2}{*}{ Kinetic constants } & \multicolumn{3}{|c|}{$A^{*}$} & \multirow{2}{*}{$t$-Value $\ln \left(A^{*}\right)$} & \multicolumn{3}{|c|}{$E_{a}(\mathrm{~kJ} / \mathrm{mol})$} & \multirow{2}{*}{$t$-Value $E_{a}$} \\
\hline & Value & LL & UL & & Value & LL & UL & \\
\hline$\tilde{k}_{i s o}(s ; s)$ & $7.21 \mathrm{E}-02$ & 4.41E-02 & $1.18 \mathrm{E}-01$ & -10.7 & 112.7 & 39.4 & 185.9 & 3.1 \\
\hline$\tilde{k}_{i s o}(s ; t)$ & $1.87 \mathrm{E}-02$ & $1.84 \mathrm{E}-03$ & $1.89 \mathrm{E}-01$ & -3.4 & 193.8 & 35.4 & 352.3 & 2.4 \\
\hline$\tilde{k}_{i s o}(t ; t)$ & $9.20 \mathrm{E}-02$ & $2.68 \mathrm{E}-02$ & $3.15 \mathrm{E}-01$ & -3.9 & 153.6 & 45.1 & 262.1 & 2.8 \\
\hline$\tilde{k}_{a l k}(s ; s)$ & $5.02 \mathrm{E}-05$ & $2.77 \mathrm{E}-05$ & $9.10 \mathrm{E}-05$ & -33.3 & 108.3 & 43.0 & 173.7 & 3.3 \\
\hline$\tilde{k}_{a l k}(s ; t)$ & $2.32 \mathrm{E}-04$ & 7.61E-05 & $7.08 \mathrm{E}-04$ & -15.0 & 110.7 & 46.1 & 175.3 & 3.4 \\
\hline$\tilde{k}_{a l k}(t ; s)$ & $1.48 \mathrm{E}-04$ & $1.34 \mathrm{E}-07$ & 1.64E-01 & -2.5 & 110.4 & 14.8 & 206.1 & 2.3 \\
\hline$\widetilde{k}_{c y c}(s ; s)$ & $2.01 \mathrm{E}+04$ & $1.79 \mathrm{E}+03$ & $2.25 \mathrm{E}+05$ & 8.2 & 78.4 & 28.9 & 128.0 & 3.2 \\
\hline$\tilde{k}_{c y c}(s ; t)$ & $9.60 \mathrm{E}+04$ & $1.33 \mathrm{E}+02$ & $6.93 \mathrm{E}+07$ & 3.5 & 307.7 & 129.2 & 486.1 & 3.4 \\
\hline$\tilde{k}_{c y c}(t ; s)$ & $1.02 \mathrm{E}+05$ & $2.77 \mathrm{E}+01$ & $3.75 \mathrm{E}+08$ & 2.8 & 306.3 & 103.4 & 509.3 & 3.0 \\
\hline $\bar{k}_{D M}(s)$ & $1.55 \mathrm{E}-03$ & $6.24 \mathrm{E}-05$ & $3.87 \mathrm{E}-02$ & -4.0 & 143.4 & 21.1 & 265.7 & 2.3 \\
\hline $\bar{k}_{D M}(t)$ & $7.21 \mathrm{E}-03$ & $2.16 \mathrm{E}-03$ & $2.41 \mathrm{E}-02$ & -8.2 & 133.5 & 40.4 & 226.5 & 2.9 \\
\hline $\bar{k}_{D M}(q)$ & $2.07 \mathrm{E}-01$ & $1.25 \mathrm{E}-01$ & $3.43 \mathrm{E}-01$ & -6.2 & 122.2 & 89.9 & 154.5 & 7.6 \\
\hline $\bar{k}_{D E}(s)$ & $1.68 \mathrm{E}-04$ & $6.19 \mathrm{E}-06$ & $4.55 \mathrm{E}-03$ & -5.3 & 228.3 & 41.6 & 415.0 & 2.4 \\
\hline $\bar{k}_{D E}(t)$ & $3.18 \mathrm{E}-03$ & $2.41 \mathrm{E}-05$ & $4.21 \mathrm{E}-01$ & -2.4 & 214.9 & 52.1 & 377.7 & 2.6 \\
\hline $\bar{k}_{D E}(q)$ & $1.97 \mathrm{E}+00$ & $1.32 \mathrm{E}+00$ & $2.94 \mathrm{E}+00$ & 3.4 & 206.8 & 163.7 & 249.9 & 9.6 \\
\hline \multirow{2}{*}{$\begin{array}{c}\text { Metal-phase } \\
\text { adsorption constants }\end{array}$} & \multicolumn{3}{|c|}{$A^{*}$} & \multirow{2}{*}{$t$-Value $\ln \left(A^{*}\right)$} & & & & \\
\hline & Value & LL & UL & & & & & \\
\hline$K_{P}$ & $4.99 \mathrm{E}+01$ & $3.14 \mathrm{E}+01$ & $7.91 \mathrm{E}+01$ & 16.9 & & & & \\
\hline$K_{N}$ & $6.21 \mathrm{E}+01$ & $3.80 \mathrm{E}+01$ & $1.01 \mathrm{E}+02$ & 16.8 & & & & \\
\hline$K_{A}$ & $1.00 \mathrm{E}+01$ & $3.20 \mathrm{E}+00$ & $3.15 \mathrm{E}+01$ & 4.0 & & & & \\
\hline
\end{tabular}

hydrogenolysis, the values are higher for deethylation than for demethylation. Moreover, within each series, the activation energies are practically the same.

The above observations suggest that, for this set of experimental data, further reduction of the number of parameters is still possible. Indeed, the three activation energies for isomerization are statistically not different, and could therefore be replaced by a unique activation energy. The same holds for the activation energies of the alkylation rate coefficients. Similarly, the statistical analysis indicates that a unique activation energy for the various demethylation rate coefficients and a unique activation energy for the various deethylation rate coefficients may suffice. This would not only further reduce the number of parameters to be identified, but may also allow to obtain more robust and statistically independent parameter values. 

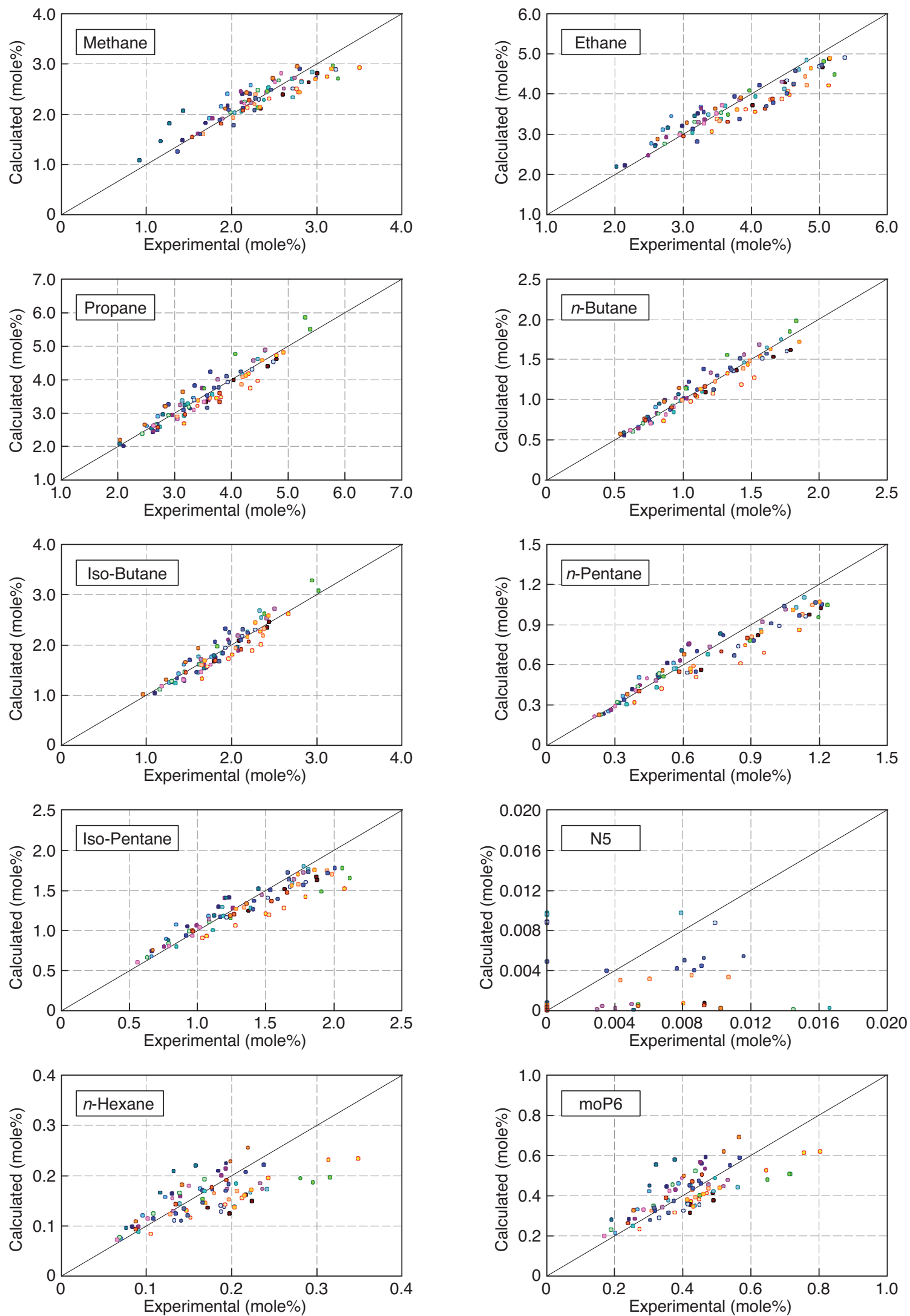

Figure 5

Comparison between experimental and simulated composition of the effluent (1st part). 

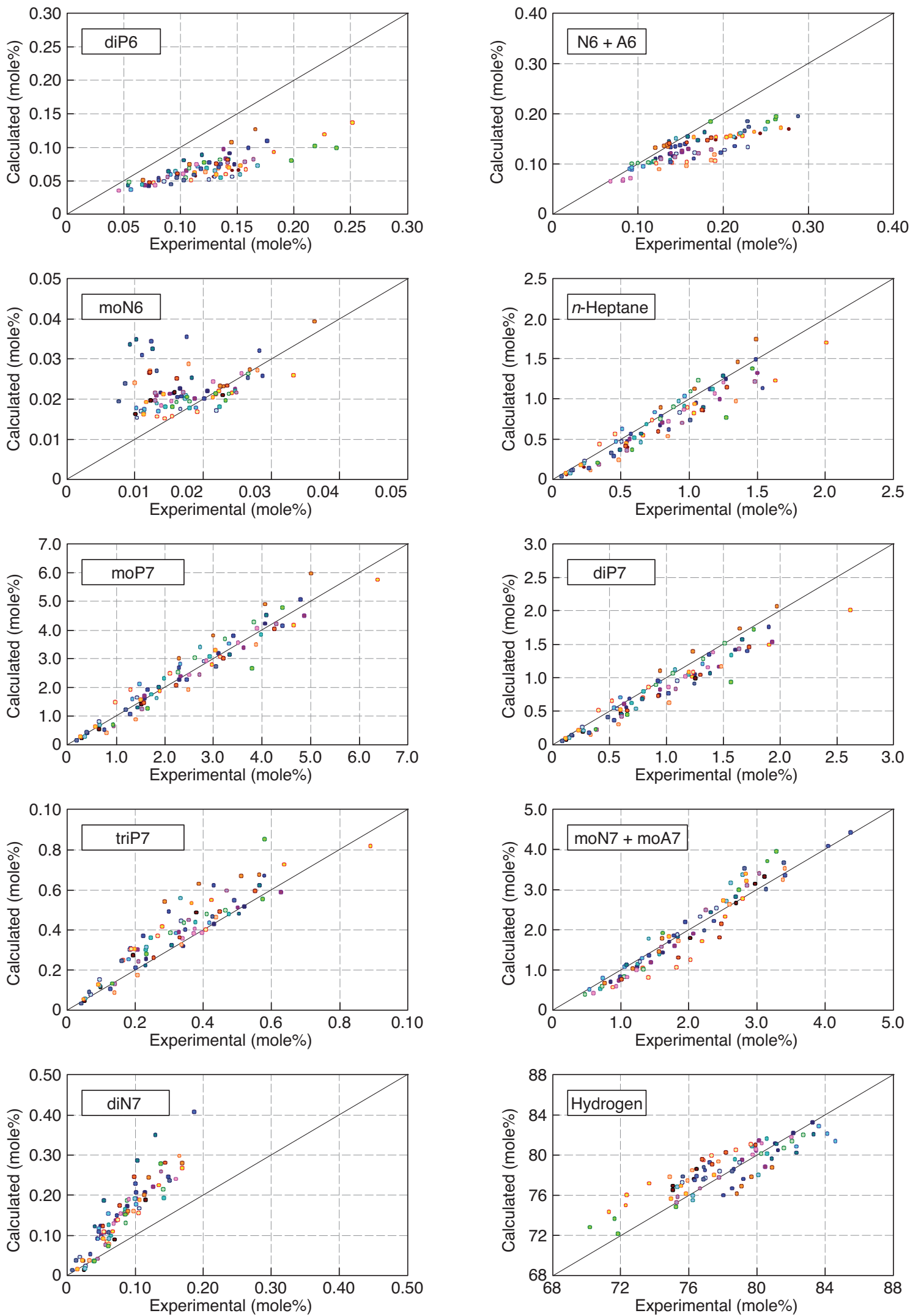

Figure 6

Comparison between experimental and simulated composition of the effluent (2nd part). 

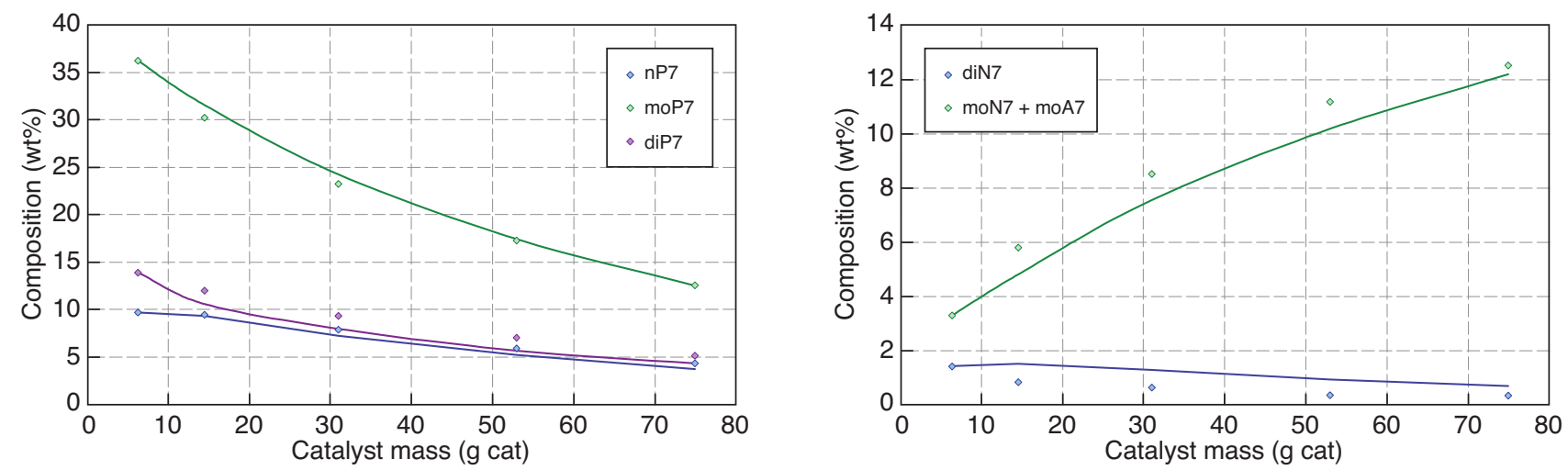

Figure 7

Evolution of the composition of the $\mathrm{C}_{7}$ fraction at a temperature of $460^{\circ} \mathrm{C}$, a total pressure of 9.5 bar and an inlet $\mathrm{H}_{2} / \mathrm{HC}$ ratio of $9 \mathrm{~mol} / \mathrm{mol}$ (points: experimental; lines: simulated).
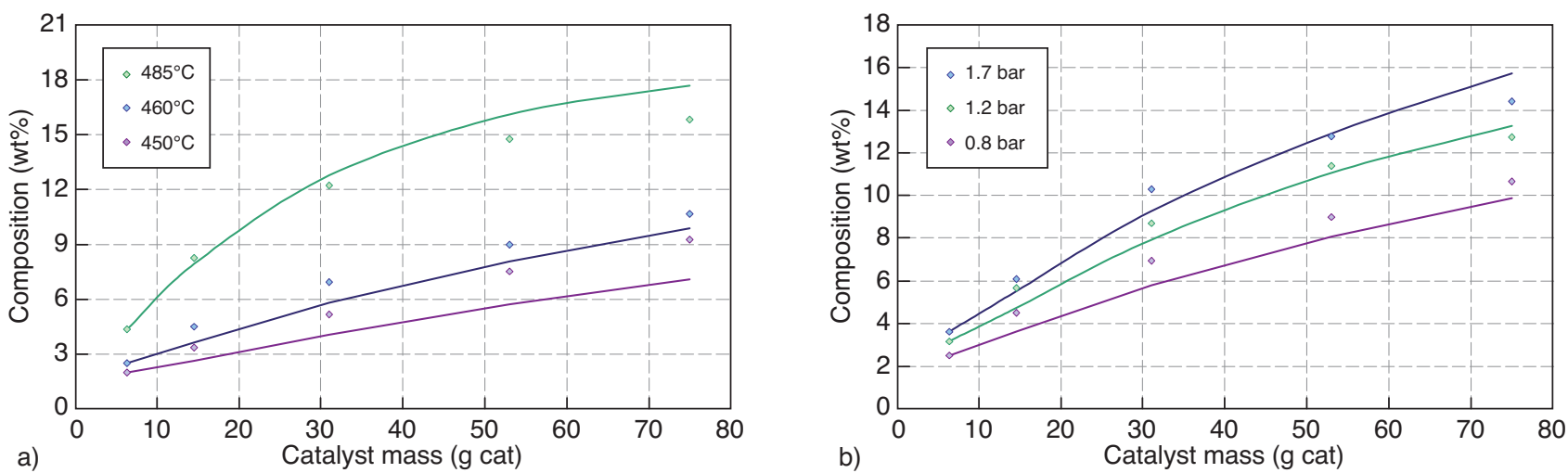

Figure 8

Effect of operating conditions on the production of the moN7+A7 lump: a) effect of temperature at a total pressure of 9.5 bar and an inlet $\mathrm{H}_{2} / \mathrm{HC}$ ratio of $12 \mathrm{~mol} / \mathrm{mol}$; b) effect of hydrocarbon partial pressure at a temperature of $460^{\circ} \mathrm{C}$, and a hydrogen partial pressure of 9.8 bar (points: experimental; lines: simulated).

\subsection{Model Predictions and Discussion}

The model predictions are in general quite satisfactory, as can be observed through the parity plots in Figure 5 and Figure 6 . The effluent mole fractions for the light products (methane, ethane, propane, butanes, pentanes and hexanes) is well described, especially given their low concentrations. The dibranched $\mathrm{C}_{6}$ compounds and benzene, however, are underestimated. For the $\mathrm{C}_{7}$ fraction, the isomerization is well predicted, since the lumps $\mathrm{nP7}, \mathrm{moP} 7$ and diP7 are correctly predicted over the entire range. The cyclization and aromatization reactions (leading to $\mathrm{moN} 7+\mathrm{moA} 7$ ) are also correctly simulated. Finally, the hydrogen content of the effluent samples is also relatively well predicted.
To illustrate the predictive power of the kinetic model, a direct confrontation of experimental and model results is also given. Figure 7 shows the evolution of the effluent composition for the various lumps of the $\mathrm{C}_{7}$ fraction at a temperature of $460^{\circ} \mathrm{C}$, a total pressure of 9.5 bar and an inlet $\mathrm{H}_{2} / \mathrm{HC}$ ratio of $9 \mathrm{~mol} / \mathrm{mol}$. A very good agreement is observed for the paraffin lumps, indicating that the isomerization, cyclization and cracking rate coefficients are well estimated. The overall production of moN7+moA7 seems somewhat too low, however, leading to a slight overestimation of the diN7 lump. This seems to indicate that the ring expansion of diN7 to moN7+moA7, either through PCP branching steps or intraring alkyl shifts, is somewhat underestimated. 

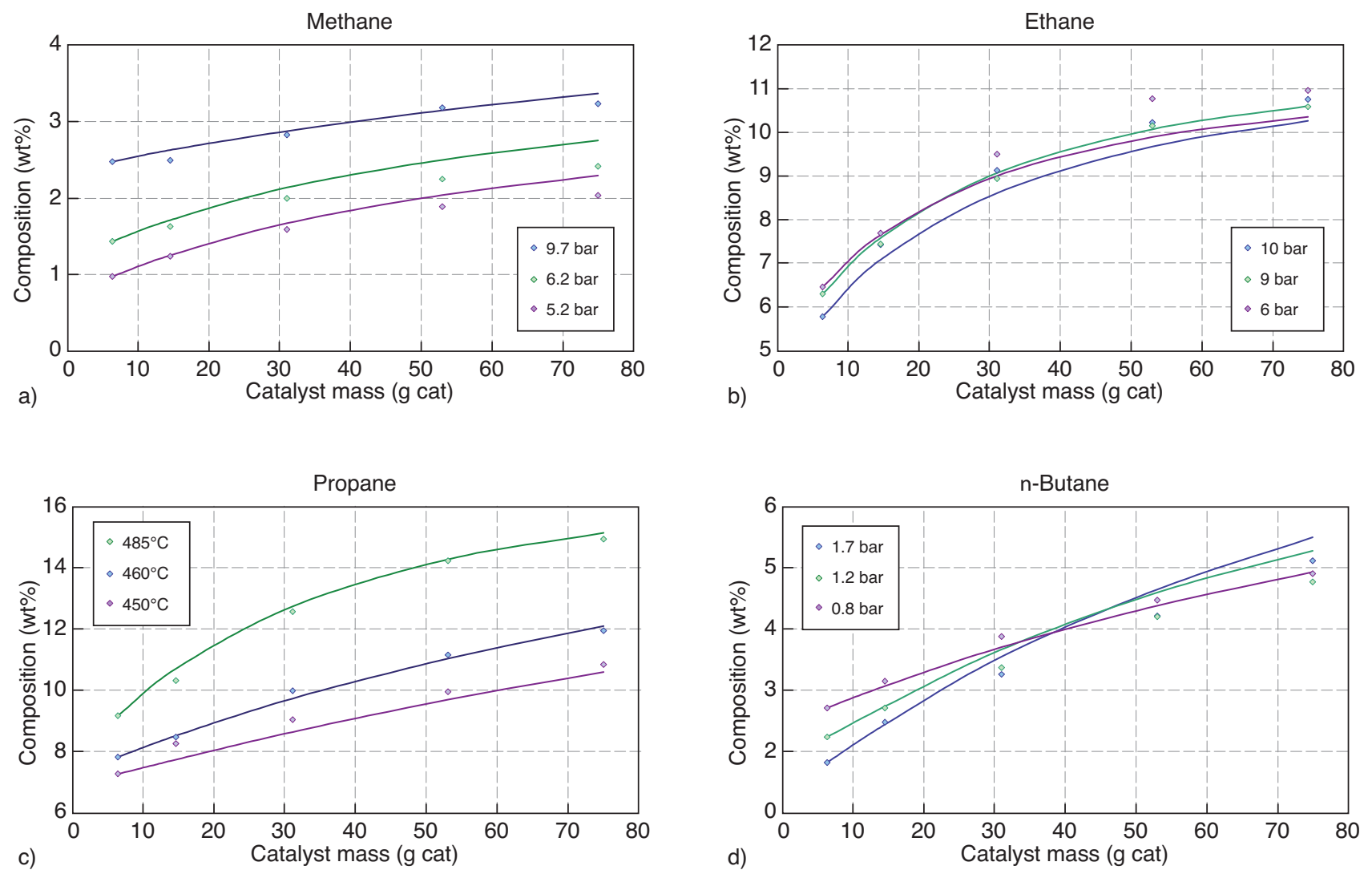

Figure 9

Effect of operating conditions on the production $\mathrm{C}_{1}$ to $\mathrm{C}_{4}$ components: a) effect of hydrogen partial pressure at a temperature of $475^{\circ} \mathrm{C}$ and a hydrocarbon partial pressure of 0.8 bar on the methane production; b) effect of total pressure at a temperature of $485^{\circ} \mathrm{C}$ and an inlet $\mathrm{H}_{2} / \mathrm{HC}$ ratio of $8 \mathrm{~mol} / \mathrm{mol}$ on the methane production; c) effect of temperature at a total pressure of 9.5 bar and an inlet $\mathrm{H}_{2} / \mathrm{HC}$ ratio of $12 \mathrm{~mol} / \mathrm{mol}$ on the propane production; c) effect of hydrocarbon partial pressure at a temperature of $460^{\circ} \mathrm{C}$ and a hydrogen partial pressure of 9.8 bar on thenbutane production (points: experimental; lines: simulated).

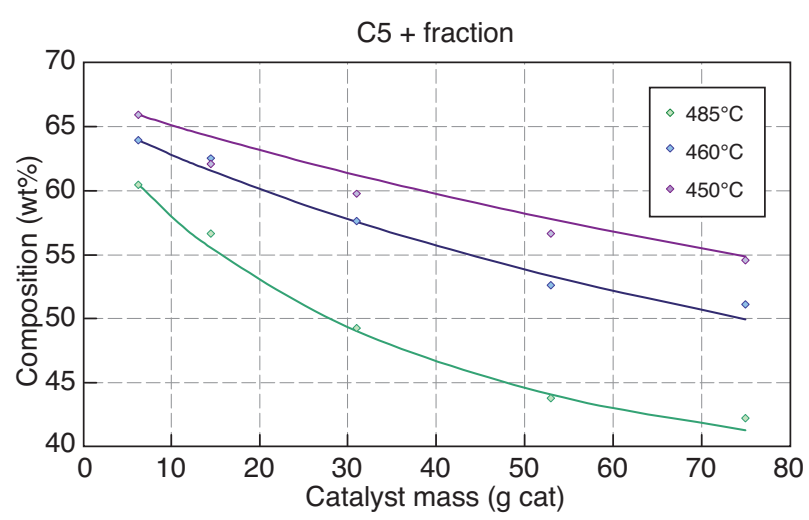

Figure 10

Evolution of the $\mathrm{C}_{5+}$ content of the reactor effluent at a total pressure of 9.5 bar and an inlet $\mathrm{H}_{2} / \mathrm{HC}$ ratio of $12 \mathrm{~mol} / \mathrm{mol}$ (points: experimental; lines: simulated).
To further investigate the prediction of the lump moN7+moA7, the effect of operating conditions was looked at in more detail. Figure 8 shows the effect of temperature and the effect of hydrocarbon partial pressure. The model responds well to the effect of hydrocarbon partial pressure, but the influence of the effect of temperature is slightly too high. This may partly be due to the relatively high values that were obtained for the activation energies for the $(s ; t)$ cyclization and the $(t ; s)$ cyclization steps.

In catalytic reforming, the prediction of the $\mathrm{C}_{5+}$ yield is very important. Figure 9 shows the evolution of the effluent composition for the $\mathrm{C}_{1}-\mathrm{C}_{4}$ fraction throughout the reactor, while Figure 10 shows effect of temperature on the $\mathrm{C}_{5_{+}}$content of the total reactor effluent. In Figure 9, a different effect of operating conditions is illustrated for the four selected components of the $\mathrm{C}_{1}-\mathrm{C}_{4}$ fraction. Overall, a very good agreement is observed for the effluent composition, both for 
the content of $\mathrm{C}_{5+}$ components and for the content of the various $\mathrm{C}_{1}-\mathrm{C}_{4}$ components.

In conclusion, the single-event kinetic model for catalytic reforming exhibits a good agreement with the experimental data and allows to correctly predict the behavior of a $\mathrm{C}_{7}$ cut. Extension to a feed with a higher number of carbon atoms only requires to add a few extra parameters (rate coefficient for $t, t \beta$-scission and adsorption coefficients for additional polycyclics) to account for reactions of species that were not present in the $\mathrm{C}_{7}$ cut. Hence, experimental data have been acquired on a $\mathrm{C}_{8}$ cut (Gauthier, 2004) in order to perform an additional validation of the single event kinetic model by predicting the reforming performances. Further validation on actual industrial feedstocks (containing components up to $\mathrm{C}_{11}$ ) is currently also being considered.

\section{CONCLUSIONS}

Refining processes based on bifunctional catalysts involve a tremendous number of species (reactants, intermediates and products) and reactions, both of which may rapidly exceed several thousands for industrial feedstocks. For the development of process models, various approaches can be considered. In most cases, the a priori lumped kinetic models by chemical family do no longer meet the current requirements in terms of simulation details, predictive power and extrapolation risks. More detailed process models are therefore required.

Due to the large number of elementary steps occurring in bifunctional catalysis, computer generation of the detailed reaction network based on simple rules offers an elegant solution. Nevertheless, it remains difficult to determine and solve the kinetic equations, mainly due to the lack of analytical detail with respect to the requirements of the detailed model.

This paper described the network generation tools and the a posteriori relumping method associated with the single-event kinetic modeling methodology. The singleevents theory allows to develop detailed kinetic models for large reaction networks and is particularly useful for reaction systems with acid and bifunctional catalysts. For many refining processes, huge reaction networks are obtained. However, reasonable assumptions on the equilibria between species allow to perform an a posteriori relumping of species and reactions. Indeed, for species with the same number of carbon atoms and branches subject to thermodynamic equilibrium, a posteriori relumping into larger groups allows to develop a kinetic network between lumps that is then strictly equivalent to the detailed network. Its size is substantially reduced, however, and this network can now be used to simulate the complete system without loss of information.

This single-event methodology, together with the a poste- riori relumping approach has been successfully applied to catalytic reforming of a $\mathrm{C}_{7}$ cut. Overall, a very good agreement between the model and the experimental data has been obtained. Future work will consist in extending the current network to higher carbon numbers and to validate the model predictions on actual industrial naphtha feeds.

\section{REFERENCES}

Al Wahabi S.M., Froment G.F. (2004) Single Event Kinetic Modeling of the Methanol-to-Olefins Process on SAPO-34, Ind. Eng. Chem. Res. 43, 17, 5098-5111.

Ancheyta-Juárez J., Villafuerte-Macías E., Díaz-García L., González-Arredondo E. (2001) Modeling and Simulation of Four Catalytic Reactors in Series for Naphtha Reforming, Energ. Fuel. 15, 4, 887-893.

Baltanas M.A., Froment G.F. (1985) Computer generation of reaction networks and calculation of product distributions in the hydroisomerization and hydrocracking of paraffins on Pt-containing bifunctional catalysts, Comp. Chem. Eng. 9, 1, 71-81.

Baltanas M.A., Van Raemdonck K.K., Froment G.F., Mohedas S.R. (1989) Fundamental kinetic modeling of hydroisomerization and hydrocracking on noble metal-loaded faujasites. 1. Rate parameters for hydroisomerization, Ind. Eng. Chem. Res. 28, 7, 899-910.

Battin-Leclerc F., Glaude P.A., Warth V., Fournet R., Scacchi G., Come G.M. (2000) Computer tools for modelling the chemical phenomena related to combustion, Chem. Eng. Sci. 55, 15, 2883-2893.

Benson S.W., Cruickshank F.R., Golden D.M., Haugen G.R., O'Neal H.E., Rodgers A.S., Shaw R., Walsch R. (1969) Additivity rules for estimation of thermodynamical properties, Chem. Rev. 69 , 279-324.

Benson S.W. (1976) Thermochemical Kinetics, 2nd Edition, John Wiley \& Sons, New York.

Blurock E.S. (1995) Reaction: System for Modeling Chemical Reactions, J. Chem. Inf. Comput. Sci. 35, 3, 607-616.

Bockhorn H. (1990) Mathematical modeling, in Ullmann's Encyclopedia of Industrial Chemistry, 5th edition, Elvers B., Hawkins S., Schultz G., Hofmann H. (eds), VCH Verlagsgesellschaft mbH, Weinheim, B1, 2.1-2.102.

Broadbelt L.J., Stark S.M., Klein M.T. (1994) Computer-generated Pyrolysis Modeling - on-the-fly Generation of Species, Reactions, and Rates, Ind. Eng. Chem. Res. 33, 4, 790-799.

Broadbelt L.J., LaMarca C., Klein M.T., Dean B.D., Andrews S.M. (1995) Chemical Modeling Analysis of Poly(aryl ether sulfone) Thermal Stability through Computer-Generated Reaction Mechanisms, Ind. Eng. Chem. Res. 34, 12, 4212-4221.

Brouwer D.M. (1980) Reactions of alkylcarbenium ions in reaction to isomerization and cracking of hydrocarbons, in Chemistry and Chemical Engineering of Catalytic Processes GCAS, Prins R. (ed), Alphen aan de Rijn, The Netherlands, Sijthoff \& Noordhoff.

Bruk L.G., Gorodskii S.N., Zeigarnik A.V., Valdés-Pérez R.E., Temkin O.N. (1998) Oxidative carbonylation of phenylacetylene catalyzed by $\mathrm{Pd}(\mathrm{II})$ and $\mathrm{Cu}(\mathrm{I})$ : Experimental tests of forty-one computer-generated mechanistic hypotheses, J. Mol. Catal. A: Chem. 130, 1-2, 29-40.

Buda F., Heyberger B., Fournet R., Glaude P.A., Warth V., BattinLeclerc F. (2006) Modeling of the gas-phase oxidation of cyclohexane, Energ. Fuel. 20, 4, 1450-1459.

Burch R., Garla L.C. (1981) Platinum-Tin Reforming Catalysts. II. Activity and Selectivity in Hydrocarbon Reactions, J. Catal. 71, 360-372 
Chavarría-Hernández J.C., Ramírez J., Gonzalez H., Baltanas M.A. (2004) Modelling of $n$-Hexadecane Hydroisomerization and Hydrocracking Reactions on a Mo/H Beta-Alumina Bi-Functional Catalyst Using the Single Event Concept, Catal. Today 98, 1-2, 235-242.

Chavarría-Hernández J.C., Ramírez J., Baltanas M.A. (2008) Single-event-lumped-parameter hybrid (SELPH) model for nonideal hydrocracking of $n$-octane, Catal. Today 130, 2-4, 455-461.

Chevalier C., Warnatz J., Melenk H. (1990) Automatic Generation of Reaction Mechanisms for Description of Oxidation of Higher Hydrocarbons, Ber. Bunsenges. Phys. Chem. 94, 1362-1367.

Chevalier C., Pitz W.J., Warnatz J., Westbrook C.K., Melenk H. (1992) Hydrocarbon Ignition: Automatic Generation of Reaction Mechanisms and Applications to Modeling of Engine Shock, Proc. Combust. Inst. 24, 1362-1367.

Chinnick S.J., Baulch D.L., Ayscough P.B. (1988) An expert system for hydrocarbon pyrolysis reactions, Chemom. Intell. Lab. Syst. $\mathbf{5}, 1,39-52$.

Christensen G., Apelian M.R., Hickey K.J., Jaffe S.B. (1999) Future directions in modeling the FCC process: An emphasis on product quality, Chem. Eng. Sci. 54, 13-14, 2753-2764.

Ciapetta F.C. (1961) Catalytic Reforming, Petro/Chem. Engr. 33, 5 , C19-C31.

Ciapetta F.C., Wallace D.N. (1971) Catalytic Naphtha Reforming, Catal.Rev. 5, 67-158.

Clymans P.J., Froment G.F. (1984) Computer generation of reaction paths and rate equations in the thermal cracking of normal and branched paraffins, Comput. Chem. Eng. 8, 2, 137-142.

Cochegrue H. (2001) Modélisation cinétique du reformage catalytique sur catalyseur $\mathrm{Pt}-\mathrm{Sn} / \mathrm{Al}_{2} \mathrm{O}_{3}, P h D$ Thesis, Université de Poitiers.

Davis B.H. (1999) Alkane dehydrocyclization mechanism, Catal. Today 53, 3, 443-516

Dente M., Pierucci S., Ranzi E., Bussani G. (1992) New improvements in modeling kinetic schemes for hydrocarbons pyrolysis reactors, Chem. Eng. Sci. 51, 2629-2634.

Dewachtere N.V., Santaella F., Froment G.F. (1999) Application of a single-event kinetic model in the simulation of an industrial riser reactor for the catalytic cracking of vacuum gas oil, Chem. Eng. Sci. 54, 15-16, 3653-3660.

DeWitt M.J., Dooling D.J., Broadbelt L.J. (2000) Computer Generation of Reaction Mechanisms Using Quantitative Rate Information: Application to Long-Chain Hydrocarbon Pyrolysis, Ind. Eng. Chem. Res. 39, 7, 2228-2237.

DiMaio F.P., Lignola P.G. (1992) KING, a Kinetic Network Generator, Chem. Eng. Sci. 47, 9-11, 2713-2718.

Faulon J.L., Sault A.G. (2001) Stochastic Generator of Chemical Structure. 3. Reaction Network Generation, J. Chem. Inf. Comp. Sci. 41, 4, 894-908.

Feng W., Vynckier E., Froment G.F. (1993) Single-event kinetics of catalytic cracking, Ind. Eng. Chem. Res. 32, 12, 2997-3005.

Fontain E., Reitsam K. (1991) The Generation of Reaction Networks with RAIN. 1. The Reaction Generator, J. Chem. Inf. Comp. Sci. 31, 1, 96-101.

Frenklach M. (1987) Modeling of large reaction systems, Complex chemical reaction systems, mathematical modelling and simulation, Springer Series in Chemical Physics, pp. 2-16.

Froment G.F., Hosten L.H. (1981) Catalytic Kinetics: Modelling, in Catalysis: Science and Technology, Anderson J.R., Boudart M. (eds), Springer-Verlag, Berlin, 2, Chapter 3, pp. 97-170.

Froment G.F. (1991) Fundamental Kinetic Modeling of Complex Processes, in Chemical Reactions in complex systems: the Mobil Workshop, Sapre A.V., Krambeck F.J. (eds), New York, Van Nostrand Reinhold, pp. 77-100.
Froment G.F. (1999) Kinetic modeling of acid-catalyzed oil refining processes, Catal. Today 52, 153-163.

Froment G.F. (2005) Single Event Kinetic Modeling of Complex Catalytic Processes, Catal. Rev. 47, 83-124.

Gates B.C., Katzer J.R., Schmit G.C.A. (1979) Chemistry of Catalytic Processes, McGraw-Hill Book Co., New York.

Gaffuri P., Faravelli T., Ranzi E., Cernansky N.P., Miller D., d'Anna A., Ciajolo A. (1997) Comprehensive kinetic model for the lowtemperature oxidation of hydrocarbons, AIChE J. 43, 5, 1278-1286.

Gauthier P. (2004) Modèle cinétique regroupé, basé sur la generation du réseau d'étapes élémentaires, du reformage catalytique régénératif, $P h D$ Thesis, Université de Poitiers.

Glaude P.A., Warth V., Fournet R., Battin-Leclerc F., Côme G.M., Scacchi G. (1997) Modelling of $n$-heptane and iso-octane gas phase oxidation at low temperature by using computer-aided designed mechanisms, B. Soc. Chim. Belg. 106, 6, 343-348.

Glaude P.A., Warth V., Fournet R., Battin-Leclerc F., Côme G.M., Scacchi G. (1998) Modelling of the oxidation of $n$-octane and $n$ decane using an automatic generation of mechanisms, Int. J. Chem. Kinet. 30, 949-959.

Green W.H., Barton P.I., Bhattacharjee B., Matheu D.M., Schwer D.A., Song J., Sumathi R., Carstensen H.H., Dean A.M., Grenda J.M. (2001) Computer Construction of Detailed Chemical Kinetic Models for Gas-Phase Reactors, Ind. Eng. Chem. Res. 40, 23, 53625370 .

Grenda J.M., Androulakis I.P., Dean A.M., Green W.H. (2003) Application of Computational Kinetic Mechanism Generation to Model the Autocatalytic Pyrolysis of Methane, Ind. Eng. Chem. Res. 42, 1000-1010.

Guillaume D., Surla K., Galtier P. (2003) From Single Events theory to molecular kinetics - application to industrial process modeling, Chem. Eng. Sci. 58, 21, 4861-4869.

Hillewaert L.P., Dierickx J.L., Froment G.F. (1988) Computer generation of reaction schemes and rate equations for thermal cracking, AIChE J. 34, 1, 17-24.

Himmelblau D.M. (1970) Process Analysis by Statistical Methods, J. Wiley and Sons, New York.

Hou G., Klein M.T. (1999) Molecular modeling of gas oil hydrodesulfurization, Abstracts of Papers of the American Chemical Society 218, U610-U611.

Iyer S.D., Joshi P.V., Klein M.T. (1998) Automated model building and modeling of alcohol oxidation in high temperature water, Environ. Prog. 17, 4, 221-233.

Ihlenfeldt W.D., Gasteiger J. (1996) Computer-Assisted Planning of Organic Syntheses: The Second Generation of Programs, Angew. Chem. (International Edition in English) 34, 23-24, 2613-2633.

Jaffe S.B., Freund H., Olmstead W.N. (2005) Extension of Structure-Oriented Lumping to Vacuum Residua, Ind. Eng. Chem. Res. 44, 26, 9840-9852.

Joshi P.V., Iyer S.D., Klein M.T. (1997) Computer assisted modeling of gas oil fluid catalytic cracking (FCC), Abstracts of Papers of the American Chemical Society 214, 80-81.

Joshi P.V., Iyer S.D., Klein M.T. (1998) Automated kinetic modelling of gas oil catalytic cracking, Rev. Process Chem. Engin. 1, 2, 110-140.

Joshi P.V., Klein M.T., Huebner A.L., Leycrle R.W. (1999) Automated kinetic modelling of catalytic reforming at the reaction pathways level, Rev. Process Chem. Engin. 2, 3, 169-193.

Katare S., Caruthers J.M., Delgass W.N., Venkatasubramanian V. (2004) An Intelligent System for Reaction Kinetic Modeling and Catalyst Design, Ind. Eng. Chem. Res. 43, 3484-3512.

Kittrell J.R. (1970) Mathematical Modeling of Chemical Reactions, Adv. Chem. Eng. 8, 97-183. 
Klein M.T., Hou G., Quann R.J., Wei W., Liao K.H., Yang R.S.H., Campain, J.A., Mazurek M.A., Broadbelt L.J. (2002) BioMol: Computer-Assisted Biological Modeling of Complex Chemical Mixtures and Biological Processes at the Molecular Level, Environ. Health Persp. 110, 6, 1025-1029.

Klein M.T., Hou G., Bertolacini R.J.., Broadbelt L.J., Kumar A. (2006) Molecular Modeling in Heavy Hydrocarbon Conversions, CRC Press, Taylor \& Francis Group, Boca Raton, FL (USA).

Klinke D.J., Broadbelt L.J. (1999) Construction of a Mechanistic Model of Fischer-Tropsch Synthesis on $\mathrm{Ni}(111)$ and $\mathrm{Co}(0001)$ Surfaces, Chem. Eng. Sci. 54, 15-16, 3379-3389.

Kmak W.S. (1971) A Kinetic Simulation Model of the Powerforming Process, Paper presented at the AIChE National Meeting, Houston, Texas, March, 3, paper 42b.

Kmak W.S., Stuckey A.N. (1973) Powerforming Process Studies with a Kinetic Simulation Model, Paper presented at the AIChE National Meeting, New Orleans, Louisiana, March, 14, paper 56a.

Kruse T.M., Woo O.S., Broadbelt L.J. (2001) Detailed mechanistic modeling of polymer degradation: application to polystyrene, Chem. Eng. Sci. 56, 3, 971-979.

Kruse T.M., Woo O.S., Wong H.W., Kahn S.S., Broadbelt L.J. (2002) Mechanistic Modeling of Polymer Degradation: A Comprehensive Study of Polystyrene, Macromolecules 35, 20, 7830-7844.

Kruse T.M., Wong H.W., Broadbelt L.J. (2003) Mechanistic Modeling of Polymer Pyrolysis: Polypropylene, Macromolecules 36, 25, 9594-9607.

Kumar H., Froment G.F. (2007a) A generalized mechanistic kinetic model for the hydroisomerization and hydrocracking of long-chain paraffins, Ind. Eng. Chem. Res. 46, 12, 4075-4090.

Kumar H., Froment G.F. (2007b) Mechanistic Kinetic Modeling of the Hydrocracking of Complex Feedstocks, such as Vacuum Gas Oils, Ind. Eng. Chem. Res. 46, 18, 5881-5897.

Laxmi Narasimhan C.S., Thybaut J.W., Marin G.B., Jacobs P.A., Martens J.A., Denayer J.F., Baron G.V. (2003) Kinetic modeling of pore mouth catalysis in the hydroconversion of $n$-octane on Pt-HZSM-22, J. Catal. 220, 2, 399-413.

Laxmi Narasimhan C.S., Thybaut J.W., Marin G.B., Denayer J.F., Baron G.V., Martens J.A., Jacobs P.A. (2004) Relumped singleevent microkinetic model for alkane hydrocracking on shape-selective catalysts: catalysis on ZSM-22 pore mouths, bridge acid sites and micropores, Chem. Eng. Sci. 59, 22-23, 4765-4772.

Levenberg K. (1944) A Method for the Solution of Certain Problems in Least Squares, Quart. Appl. Math. 2, 2, 164-168.

Levine S.E., Broadbelt L.J. (2009) Detailed mechanistic modeling of high-density polyethylene pyrolysis: Low molecular weight product evolution, Polym. Degrad.Stab. 94, 5, 810-822.

Lozano-Blanco G., Thybaut J.W., Surla K., Galtier P., Marin G.B. (2006) Fischer-Tropsch Synthesis: Development of a Microkinetic Model for Metal Catalysis, Oil Gas Sci. Technology - Rev. IFP 61, 4, 489-496.

Lozano-Blanco G., Thybaut J.W., Surla K., Galtier P., Marin G.B. (2008) Single-Event Microkinetic Model for Fischer-Tropsch Synthesis on Iron-Based Catalysts, Ind. Eng. Chem. Res. 47, 16, 5879-5891.

Maire G.L.C., Garin F.G. (1984) Metal Catalyzed Skeletal Reactions of Hydrocarbons, in Catalysis: Science and Technology, Anderson J.R., Boudart M. (eds), Springer-Verlag, Berlin, 6, Chapter 3, pp. 162-226.

Marcilly C. (2003) Catalyse acido-basique. Volume 1 - Volume 2, Editions Technip, Paris.

Marin G.B., Froment G.F. (1982) Reforming of $\mathrm{C}_{6}$-Hydrocarbons on a Pt/ $\mathrm{Al}_{2} \mathrm{O}_{3}$ Catalyst, Chem. Eng. Sci. 37, 5, 759-773.
Marin G.B., Froment G.F., Lerou J.J., De Backer W. (1983) Simulation of a Catalytic Naphtha Reforming Unit, Proc. 3rd Int. Congress on Computers and Chemical Engineering, E.F.C.E. Publication Series No. 27, Vol. II, C117/1 - C117/7, Paris.

Marin G.B., Froment G.F. (1990) The Development and Use of Rate Equations for Catalytic Refinery Processes, Proc. 1st Kuwait Conference on Hydrotreating Processes, Kuwait, 1989, March 5-9, published in Catalysts in Petroleum Refining 1989, Trimm D.L. et al. (eds), Elsevier Science Publishers B.V., Amsterdam, pp. 497-511.

Marquardt D. (1963) An Algorithm for Least-Squares Estimation of Nonlinear Parameters, J. Soc. Ind. Appl . Math. 11, 2, 431-441.

Martens G.G., Froment G.F. (1999) Kinetic modeling of paraffins hydrocracking based upon elementary steps and the single event concept, in Reaction kinetics and the development of catalytic processes, Froment G.F., Waugh K.C. (eds), Elsevier Science BV, Stud. Surf. Sci. Catal. 122, 333-340

Martens G.G., Marin G.B., Martens J.A., Jacobs P.A., Baron G.V. (2000) A fundamental kinetic model for hydrocracking of C8 to C12 alkanes on Pt/US-Y zeolites, J. Catal. 195, 2, 253-267.

Martens G.G., Thybaut J.W., Marin G.B. (2001) Single event rate parameters for hydrocracking of cycloalkanes on Pt/US-Y zeolites, Ind. Eng. Chem. Res. 40, 8, 1832-1844.

Martinis J.M., Froment G.F. (2006) Alkylation on Solid Acids. Part 2. Single-Event Kinetic Modeling, Ind. Eng. Chem. Res. 45, 954-967.

Martino G. (1998) Le raffinage du pétrole. 3. Procédés de transformation, Leprince P. (ed), Editions Technip, Paris, France, Chap. 4, pp. 105-173.

Matheu D.M., Lada T.A., Green, W.H., Dean A.M., Grenda J.M. (2001) Rate-based screening of pressure-dependent reaction networks, Comput. Phys. Commun. 138, 3, 237-249.

Matheu D.M., Dean A.M., Grenda J.M., Green W.H. (2003) Mechanism Generation with Integrated Pressure dependence: A New Model for Methane Pyrolysis, J. Phys. Chem. A 107, 85528565.

Mills G.A., Heinemann H., Milliken T.H., Oblad A.G. (1953) Houdriforming reactions: Catalytic Mechanism, Ind. Eng. Chem. 45, 1, 134-137.

Mitsios M., Guillaume D., Galtier P., Schweich D. (2009) SingleEvent Microkinetic Model for Long-Chain Paraffin Hydrocracking and Hydroisomerization on an Amorphous $\mathrm{Pt} / \mathrm{SiO}_{2}-\mathrm{Al}_{2} \mathrm{O}_{3}$ Catalyst, Ind. Eng. Chem. Res. 48, 3284-3292.

Mizan T.I., Klein M.T. (1999) Computer-assisted mechanistic modeling of $n$-hexadecane hydroisomerization over various bifunctional catalysts, Catal. Today 50, 1, 159-172

Moustafa T., Froment G.F. (2003) Kinetic Modeling of Coke Formation and Deactivation in the Catalytic Cracking of Vacuum Gas Oil, Ind. Eng. Chem. Res. 42, 1, 14-25.

Németh A., Vidóczy T., Héberger K., Kúti Z., Wágner J. (2002) MECHGEN: Computer Aided Generation and Reduction of Reaction Mechanisms, J. Chem. Inf. Comput. Sci. 42, 2, 208-214.

Olah G.A., Prakash G.K.S., Sommer J. (1985) Superacids, New York.

Park T.-Y., Froment G.F. (2001) Kinetic Modeling of the MTO Process - I. Model Formulation, Ind. Eng. Chem. Res. 40, 20, 4172-4186.

Park T.-Y., Froment GF (2004) Analysis of fundamental reaction rates in the methanol-to-olefins process on ZSM-5 as a basis for reactor design and operation, Ind. Eng. Chem. Res. 43, 3, 682-689.

Pfaendtner J., Broadbelt L.J. (2008a) Mechanistic Modeling of Lubricant Degradation. 1. Structure - Reactivity Relationships for Free-Radical Oxidation, Ind. Eng. Chem. Res. 47, 9, 2886-2896. 
Pfaendtner J., Broadbelt L.J. (2008b) Mechanistic Modeling of Lubricant Degradation. 2. The Autoxidation of Decane and Octane, Ind. Eng. Chem. Res. 47, 9, 2897-2904

Prickett S.E., Mavrovouniotis M.L. (1997a) Construction of Complex Reaction Systems - I. Reaction description language, Comput. Chem. Eng. 21, 11, 1219-1235.

Prickett S.E., Mavrovouniotis M.L. (1997b) Construction of Complex Reaction Systems - II. Molecule manipulation and reaction application algorithms, Comput. Chem. Eng. 21, 11, 12371254.

Prickett S.E., Mavrovouniotis M.L. (1997c) Construction of Complex Reaction Systems - III. An example: alkylation of olefins, Comput. Chem. Eng. 21, 12, 1325-1337.

Quann R.J., Jaffe S.B. (1992) Structure-oriented lumping: describing the chemistry of complex hydrocarbon mixtures, Ind. Eng. Chem. Res. 31, 11, 2483-2497.

Quann R.J., Jaffe S.B. (1996) Building useful models of complex reaction systems in petroleum refining, Chem. Eng. Sci. 51, 10, 1615-1635.

Quann R.J. (1998) Modeling the Chemistry of Complex Petroleum Mixtures, Environ. Health Persp. 106, 6, 1441-1448.

Quintana-Solórzano R., Thybaut J.W., Marin G.B., Lødeng R., Holmen A. (2005) Single-Event MicroKinetics for coke formation in catalytic cracking, Catal. Today 107, 8, 619-629.

Quintana-Solórzano R., Thybaut J.W., Marin G.B. (2007a) A single-event microkinetic analysis of the catalytic cracking of (cyclo)alkanes on an equilibrium catalyst in the absence of coke formation, Chem. Eng. Sci. 62, 18-20, 5033-5038.

Quintana-Solórzano R., Thybaut J.W., Galtier P., Marin G.B. (2007b) Single-Event MicroKinetics for coke formation during the catalytic cracking of (cyclo)alkane/1-octene mixtures, Catal. Today 127, 1, 17-30.

Ramage M.P., Graziani K.R., Krambeck F.J. (1980) Development of Mobil's Reforming Model, Chem. Eng. Sci. 35, 1, 41-48

Ramage M.P., Graziani K.R., Schipper P.H., Krambeck F.J., Choi B.C. (1987) KINPtR (Mobil's Kinetic Reforming Model): A Review of Mobil's Industrial Process Modeling Philosophy, in $A d v$. Chem. Eng., Wei J., Anderson J.L., Bischoff K.B., Denn M.M., Seinfeld J.H. (eds), Academic Press, Orlando, 13, 193-266

Ranzi E., Faravelli T., Gaffuri P., Sogaro A. (1995) Low Temperature Combustion - Automatic-Generation of Oxidation Reactions and Lumping procedures, Combust. Flame 102, 179-192.

Ratkiewicz A., Truong T.N. (2003) Application of Chemical Graph Theory for Automated Mechanism Generation, J. Chem. Inf. Comput. Sci. 43, 36-44.

Ratkiewicz A., Truong T.N. (2006) Automated mechanism generation: From symbolic calculation to complex chemistry, Int. J. Quantum Chem. 106, 1, 244-255.

Sapre A.V. (1991) Kinetic Modelling at Mobil: A Historical Perspective, in Chemical Reactions in Complex Mixtures: the Mobil Workshop, Sapre A.V., Krambeck F.J. (eds), Van Nostrand Reinhold, New York, Chap. 12, pp. 222-253.

Schipper P.H., Graziani K.R., Choi B.C., Ramage M.P. (1984) The Extension of Mobil's Kinetic Reforming Model to include Catalyst Deactivation, Int. Chem. Eng. Symp. Ser. 87, 33-44.

Sinfelt J.H., Hurwitz H., Rohrer J.C. (1960) Kinetics of $n$-Pentane Isomerization over $\mathrm{Pt} / \mathrm{Al}_{2} \mathrm{O}_{3}$ Catalyst, J. Phys. Chem. 64, 892-894.

Sinfelt J.H., Hurwitz H., Rohrer J.C. (1962) Role of Dehydrogenation Activity in Catalytic Isomerization and Dehydrocyclization of Hydrocarbons, J. Catal. 1, 481-483.

Sinfelt J.H. (1981) Catalytic Reforming of Hydrocarbons, in Catalysis: Science and Technology, Anderson J.R., Boudart M. (eds), Springer-Verlag, Berlin, Vol. 1, Chap. 5, pp. 257-300.
Sinfelt J.H. (1997) Handbook of Heterogeneous Catalysis, Part B: Catalytic Processes, Ertl G., Knozinger H., Weitkamp J. (eds), Wiley-VCH, Weinheim, Germany, Vol. 4, pp. 1939-1954.

Song J., Raman S., Yu J., Wijaya C.D., Stephanopoulos G., Green W.H. (2003) Development of Automatic Chemical Reaction Mechanism Generation Software Using Object-Oriented Technology, Prepr. Pap. - Am. Chem. Soc., Div. Fuel Chem. 48, 2, 516-517.

Sotelo-Boyás R., Froment G.F. (2009) Fundamental Kinetic Modeling of Catalytic Reforming, Ind. Eng. Chem. Res. 48, 3, 1107-1119

Souverijns W., Parton R., Martens J.A., Froment G.F., Jacobs P.A. (1996) Mechanism of the paring reaction of naphtenes, Catal. Lett. 37, 3-4, 207-212.

Sterba M.J., Haensel V. (1976) Catalytic Reforming, Ind. Eng. Chem. Prod.Res. Dev. 15, 1, 2-17

Sullivan R.F., Egan C.J., Langlois G.E., Sieg R.P. (1961) A New Reaction That Occurs in the Hydrocracking of Certain Aromatic Hydrocarbons, J. Am. Chem. Soc. 83, 5, 1156-1160.

Surla K., Guillaume D., Verstraete J.J., Galtier P. (2011) Single Event Kinetic Modeling: application to isomerization of light paraffins, Oil Gas Sci. Technol., 66, 343-365.

Susnow R.G., Dean A.M., Green W.H., Peczak P., Broadbelt L.J. (1997) Rate-Based Construction of Kinetic Models for Complex Systems, J. Phys. Chem. A 101, 20, 3731-3740.

Svoboda G.D., Vynckier E., Debrabandere B., Froment G.F. (1995) Single-Event Rate Parameters for Paraffin Hydrocracking on a Pt/US-Y Zeolite, Ind. Eng. Chem. Res. 34, 11, 3793-3800.

Temkin O.N., Zeigarnik A.V., Kuz'min A.E., Bruk L.G., Slivinskii E.V. (2002) Construction of the reaction networks for heterogeneous catalytic reactions: Fischer-Tropsch synthesis and related reactions, Russ. Chem. Bull. Int. Ed. 51, 1, 1-36.

Thybaut J.W., Marin G.B. (2003) Kinetic Modeling of the Conversion of Complex Hydrocarbon Feedstocks by Acid Catalysis, Chem. Eng. Technol. 26, 4, 509-514.

Tomlin A.S., Turányi T., Pilling M.J. (1997) Mathematical tools for the construction, investigation and reduction of combustion mechanisms, in Low-Temperature Combustion and Autoignition, Pilling M.J. (ed) Elsevier, Amsterdam.

True W.R., Koottungal L. (2010) Global capacity growth slows, but Asian refineries bustle, Oil Gas J. 108, 46, 50-59.

Ugi I., Bauer J., Bley K., Dengler A., Dietz A., Fontain E., Gruber B., Herges R., Knauer M., Reitsam K., Stein N. (1993) Computer Assisted Solution of Chemical Problems - The Historical Development and the Present State of the Art of a New Discipline of Chemistry, Angew. Chem. Int. Ed. Engl. 32, 201-227.

Van Geem K.M., Reyniers M.F., Marin G.B., Song J., Mattheu D.M., Green W.H. (2006) Automatic Network generation using RMG for Steam Cracking of $n$-Hexane, AIChE J. 52, 2, 718-730.

Van Geem K.M., Reyniers M.F., Marin G.B. (2008) Challenges of Modeling Steam Cracking of Heavy Feedstocks, Oil Gas Sci. Technol. - Rev. IFP 63, 1, 79-94.

Van Trimpont P.A., Marin G.B., Froment G.F. (1985) Activities and Selectivities for Reforming Reactions on Unsulphided and Sulphided Commercial Platinum and Platinum-Rhenium Catalysts, Appl. Catal. 17, 1, 161-173.

Van Trimpont P.A., Marin G.B., Froment G.F. (1986a) Kinetics of Methyl cyclohexane Dehydrogenation on Sulphided Commercial $\mathrm{Pt} / \mathrm{Al}_{2} \mathrm{O}_{3}$ and Pt-Re/Al $\mathrm{O}_{3}$ Catalysts, Ind. Eng. Chem. Fund. 25, 4, 544-553.

Van Trimpont P.A., Marin G.B., Froment G.F. (1986b) Kinetics of the Reforming of $\mathrm{C}_{7}$-Hydrocarbons on a Commercial Pt-Re/ $/ \mathrm{Al}_{2} \mathrm{O}_{3}$ Catalyst, Appl. Catal. 24, 1, 53-68 
Van Trimpont P.A., Marin G.B., Froment G.F. (1988) Reforming of $\mathrm{C}_{7}$-Hydrocarbons on a Sulphided Commercial $\mathrm{Pt} / \mathrm{Al}_{2} \mathrm{O}_{3}$ Catalyst, Ind. Eng. Chem. Res. 27, 1, 51-57.

Verstraete J. (1997) Kinetische Studie van de Katalytische Reforming van Nafta over een Pt-Sn/ $\mathrm{Al}_{2} \mathrm{O}_{3}$ Katalysator, $P h D$ Thesis, Universiteit Gent.

Vleduts G.E. (1963) Concerning One System of Classification and Codification of Organic Reactions, Inf. Storage Retr. 1, 117-146.

Vynckier E., Froment G.F. (1991) Modeling of the kinetics of complex processes upon elementary steps, in Kinetic and thermodynamic lumping of multicomponent mixtures, Astarita G., Sandler S.I. (eds), Elsevier Science Publishers BV, Amsterdam, pp. 131-161.

Warth V., Battin-Leclerc F., Fournet R., Glaude P.A., Come G.M., Scacchi G. (2000) Computer based generation of reaction mechanisms for gas-phase oxidation, Comput. Chem. 24, 541-560.

Wei W., Bennett C.A., Tanaka R., Hou G., Klein M.T. (2008) Detailed kinetic models for catalytic reforming, Fuel Process. Technol.89, 4, 344-349.
Weitkamp J., Ernst S., Karge H.G. (1984) Peculiarities in the Conversion of Naphthenes on Bifunctional Catalysts, Erdöl und Kohle, Erdgas, Petrochemie vereinigt mit Brennstoff-Chemie 37, 10, 457-462.

Willems P.A., Froment G.F. (1988a) Kinetic Modeling of the Thermal Cracking of Hydrocarbons. 1. Calculation of Frequency Factors, Ind. Eng. Chem. Res. 27, 11, 1959-1966.

Willems P.A., Froment G.F. (1988b) Kinetic Modeling of the Thermal Cracking of Hydrocarbons. 2. Calculation of Activation Energies, Ind.Eng. Chem. Res. 27, 11, 1966-1971.

Wong H.W., Li X., Swihart M.T., Broadbelt L.J. (2004) Detailed Kinetic Modeling of Silicon Nanoparticle Formation Chemistry via Automated Mechanism Generation, J. Phys. Chem. A 108, 46, 10122-10132.

Zeigarnik A.V., Valdés-Pérez R.E., Temkin O.N., Bruk L.G., Shalgunov S.I. (1997) Computer-Aided Mechanism Elucidation of Acetylene Hydrocarboxylation to Acrylic Acid Based on a Novel Union of Empirical and Formal Methods, Organometallics 16, 14, 3114-3127.

Final manuscript received in May 2011 Published online in July 2011 